Check for updates

Cite this: Phys. Chem. Chem. Phys., 2020, 22, 19326

Received 3rd June 2020, Accepted 10th August 2020

DOI: $10.1039 / \mathrm{d} 0 \mathrm{cp02977g}$

rsc.li/pccp

\section{Large-scale comparison of $3 d$ and $4 d$ transition metal complexes illuminates the reduced effect of exchange on second-row spin-state energetics $\dagger$}

\author{
Aditya Nandy, (D) $\ddagger^{\mathrm{ab}}$ Daniel B. K. Chu, (D) $\ddagger^{\mathrm{a}}$ Daniel R. Harper, ${ }^{\mathrm{ab}}$ Chenru Duan, ${ }^{\mathrm{ab}}$ \\ Naveen Arunachalam, (D) ${ }^{a}$ Yael Cytter ${ }^{a}$ and Heather J. Kulik (D) *a
}

\begin{abstract}
Density functional theory (DFT) is widely used in transition-metal chemistry, yet essential properties such as spin-state energetics in transition-metal complexes (TMCS) are well known to be sensitive to the choice of the exchange-correlation functional. Increasing the amount of exchange in a functional typically shifts the preferred ground state in first-row TMCs from low-spin to high-spin by penalizing delocalization error, but the effect on properties of second-row complexes is less well known. We compare the exchange sensitivity of adiabatic spin-splitting energies in pairs of mononuclear $3 \mathrm{~d}$ and $4 \mathrm{~d}$ mid-row octahedral transition-metal complexes. We analyze hundreds of complexes assembled from four metals in two oxidation states with ten small monodentate ligands that span a wide range of field strengths expected to favor a variety of ground states. We observe consistently lower but proportional sensitivity to exchange fraction among 4d TMCs with respect to their isovalent 3d TMC counterparts, leading to the largest difference in sensitivities for the strongest field ligands. The combined effect of reduced exchange sensitivities and the greater low-spin bias of most 4d TMCs means that while over one-third of 3d TMCs change ground states over a modest variation (ca. 0.0-0.3) in exchange fraction, almost no 4d TMCs do. Differences in delocalization, as judged through changes in the metal-ligand bond lengths between spin states, do not explain the distinct behavior of $4 d$ TMCs. Instead, evaluation of potential energy curves in $3 d$ and $4 d$ TMCs reveals that higher exchange sensitivities in $3 d$ TMCs are likely due to the opposing effect of exchange on the low-spin and high-spin states, whereas the effect on both spin states is more comparable in $4 d$ TMCs.
\end{abstract}

\section{Introduction}

Approximate density functional theory (DFT) is widely used in studying the catalytic ${ }^{1-6}$ and materials ${ }^{7-13}$ properties of openshell transition-metal complexes. ${ }^{14}$ The well-localized $d$ or $f$ electrons of open-shell transition-metal centers impart unique properties but also can lead to a significant number of low-energy spin and oxidation states that are challenging to describe on equal footing using approximate electronic structure methods. For DFT in particular, presently available exchangecorrelation (xc) approximations suffer from one- and manyelectron self-interaction errors, ${ }^{15-19}$ commonly referred to as delocalization error $^{20-22}(\mathrm{DE})$.

The high earth abundance and prevalence of $3 \mathrm{~d}$ transition metals in enzymatic systems has motivated the widespread study ${ }^{16,23-41}$ of electronic structure method accuracy in firstrow transition-metal complexes. For 3d transition-metal chemistry, DE can lead to pronounced errors in calculated bond dissociation energies, ${ }^{16,23-27}$ barrier heights, ${ }^{28,29}$ and properties of the density ${ }^{30-33}$ within a given spin state as well as the relative 
energetic ordering of spin states. ${ }^{29,34-41}$ While in some cases, it is possible to use higher accuracy methods such as correlated wavefunction theory, such methods have their own challenges in open-shell transition-metal complex (TMC) property prediction accuracy ${ }^{42-45}$ and remain cost-prohibitive for large-scale discovery of new TMCs. ${ }^{46-51}$

Although less earth abundant than $3 \mathrm{~d}$ metals, $4 \mathrm{~d}$ transition metals often form catalysts with superior catalytic activity and turnover number (e.g., $\mathrm{Ru}^{52-54}$ for water oxidation and $\mathrm{Mo}^{55}$ for hydrogen evolution) and are excellent photosensitizers. ${ }^{56}$ Despite this importance of $4 \mathrm{~d}$ transition metals, comparatively less is known about the relative accuracy of electronic structure methods for these TMCs. ${ }^{57-59}$ While we can anticipate that there should be some transferable observations between $3 \mathrm{~d}$ and $4 \mathrm{~d}$ metals, a more detailed understanding of the relationship between $3 \mathrm{~d}$ and $4 \mathrm{~d}$ TMC sensitivity to method choice is needed.

Broadly, the need to balance cost and accuracy has motivated a number of strategies aimed at efficiently eliminating DE in approximate DFT by recovering the derivative discontinuity ${ }^{60}$ lacking from pure (i.e., generalized gradient approximation or GGA) functionals. ${ }^{15,61-66}$ Approaches have included selfinteraction $^{67-69}$ and closely related DFT $+U^{70-73}$ corrections, tailoring higher order terms in the xc functional, $37,40,45,74-85$ or incorporating an admixture ${ }^{32,33,86-102}$ of Hartree-Fock (HF) exchange globally or with range-separation in a GGA. All such strategies generally behave similarly in TMCs by decreasing covalency $^{33}$ or dative bonding ${ }^{32,103-105}$ and localizing density away from the metal. ${ }^{30,37}$ Functional tuning for either $3 \mathrm{~d}$ or $4 \mathrm{~d}$ transition-metal chemistry is challenged ${ }^{106}$ both by the limited availability of reference data and the highly system- and property-specific nature of optimal functional choice, ${ }^{29,35-37,107-112}$ although physically motivated tuning approaches have been developed for select cases. ${ }^{113-115}$ Still, tuning the global amount of HF exchange (i.e., $a_{\mathrm{HF}}$ ) in a GGA hybrid remains one of the most widely used approaches to improving approximate DFT errors.

For 3d midrow, octahedral TMCs, it is well known that the ground state is highly sensitive to the fraction of HF exchange due to the near-degeneracy of multiple spin states in these complexes ${ }^{36,82,116-119}$ as well as the close relationship between spin-state stabilization and DEs in approximate DFT. ${ }^{30,111}$ Pure, semi-local GGA functionals ${ }^{120,121}$ consistently stabilize overlydelocalized, ${ }^{18,30}$ strongly covalent states, ${ }^{33}$ tending to favor the increased bonding in low-spin (LS) over high-spin (HS) states. $^{29,39,70,77,122-125}$ This manifestation of DE leads GGAs to predict incorrect ground states as well as relative energies ${ }^{14,124,125}$ between spin states (e.g., adiabatic HS to LS spin splitting, $\Delta E_{\mathrm{H}-\mathrm{L}}$ ). Hybrid functionals counteract ${ }^{35-37,118,126-129}$ the bias for LS states, but the appropriate fraction of HF exchange is strongly system dependent. $^{35-37,108-111,130}$ For 3d TMCs, conflicting proposals of low (as little as $\left.a_{\mathrm{HF}}=0.0\right)^{35,117,131,132}$ and high $\left(a_{\mathrm{HF}}=\right.$ 0.4-0.5) ${ }^{31,36,40,133,134}$ fractions have been recommended, but $4 \mathrm{~d}$ TMCs do not have similar heuristics.

In this work we apply our pragmatic approach of understanding the linearized ${ }^{29-31,37,39}$ exchange sensitivity of spinsplitting energies ${ }^{35-37,108,117,131,132}$ simultaneously to $3 \mathrm{~d}$ and $4 \mathrm{~d}$
TMC spin-state energetics. In 3d TMCs, this spin-state ordering exchange sensitivity is correlated to the ligand field strength of coordinating ligands, ${ }^{37,108}$ with bare ions exhibiting reduced sensitivities $^{39}$ in comparison to strong-field ligands. For common ligands in mid-row, 3d TMCs, this exchange sensitivity can be significant, leading to a change in $\Delta E_{\mathrm{H}-\mathrm{L}}$ on the order of 10-20 kcal mol ${ }^{-1}$ for a change in HF exchange from $a_{\mathrm{HF}}=0.15$ (e.g. in $\left.\mathrm{B}_{3} \mathrm{LYP}^{* 132}\right)$ to $a_{\mathrm{HF}}=0.25$ (e.g., in $\left.\mathrm{PBE0}^{135}\right)$. While the form of the pure GGA xc being tuned (e.g., BLYP vs. PBE) can influence $\Delta E_{\mathrm{H}-\mathrm{L}}$, the $\mathrm{HF}$ exchange sensitivity has been shown to be invariant to GGA choice in 3d TMCs. ${ }^{37,39,40}$ These strong relationships between chemical structure and method sensitivity in 3d TMCs have enabled the development of machine learning models to predict exchange sensitivity and exchange-dependent properties, enlarging understanding of how changes in functional definition can influence large-scale discovery efforts. ${ }^{136-139}$

Although these relationships have been established and fruitfully applied for $3 \mathrm{~d}$ TMCs, the sensitivity of second-row (i.e., 4d) TMCs to HF exchange is not well known. In this work, we carry out a large-scale study of hundreds of mononuclear octahedral TMCs to understand broad relationships among first- and second-row spin-state ordering and exchange sensitivity. In Section 2, we describe how we construct a data set in which both the $3 \mathrm{~d}$ and an isovalent $4 \mathrm{~d}$ metal complex's properties and sensitivity to exchange are known for mid-row transition metals in low-, intermediate-, and high-spin states. In Section 3, we discuss our results on quantifying distinct behavior in ground state preference and sensitivity to HF exchange fraction for the second-row complexes. We identify sources for this difference by noting distinct effects of exchange on each spin state's potential energy surface in $3 \mathrm{~d}$ and $4 \mathrm{~d}$ TMCs. Finally, in Section 4 , we provide our conclusions.

\section{Computational details}

\section{a. Data set construction}

We studied the effect of HF exchange on the spin-state ordering of octahedral TMCs with a single mid-row transition-metal center. We compared properties of TMCs comprised of firstrow (i.e., 3d valence) $\mathrm{Cr}, \mathrm{Mn}, \mathrm{Fe}$, and Co to second-row (i.e., $4 \mathrm{~d}$ valence) Mo, Tc, Ru, and Rh (Fig. 1). In all cases, we calculated properties of metal centers in formal M(II) or M(III) oxidation states to ensure differences in spin state correspond to differences in d orbital occupations (Fig. 1). The TMCs were evaluated in up to three spin states: low-spin (LS), intermediate-spin (IS), and high-spin (HS), where we defined the IS and HS states as those that differ from the LS state (i.e., with $l s$ unpaired electrons) by two more (i.e., $l s+2$ ) or four more (i.e., $l s+4$ ) unpaired electrons, respectively. We then computed the gas phase, adiabatic spin-splitting energy: between the LS and HS states, $\Delta E_{\mathrm{H}-\mathrm{L}}$, as well as between the IS state and either the HS or the LS state (i.e., $\Delta E_{\mathrm{H}-\mathrm{I}}$ and $\Delta E_{\mathrm{I}-\mathrm{L}}$ ). The nominally $\mathrm{d}^{3} \mathrm{Cr}(\mathrm{III}) /$ $\mathrm{Mo}(\mathrm{III})$ and $\mathrm{d}^{7} \mathrm{Co}(\mathrm{II}) / \mathrm{Rh}$ (II) were evaluated only in LS doublet and IS quartet spin multiplicities (i.e., also the highest accessible spin state), and only $\Delta E_{\mathrm{I}-\mathrm{L}}$ was computed (Fig. 1 ). The $\mathrm{d}^{5}$ metals 


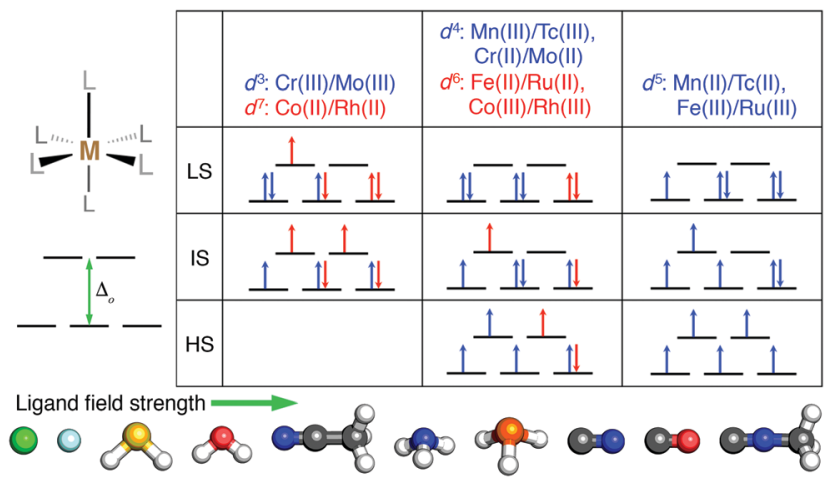

Fig. 1 (top) Qualitative diagrams of electron configurations in low-spin (LS), intermediate-spin (IS), and high-spin (HS) states for the mononuclear octahedral transition-metal complexes studied in this work (schematically shown at left). For both $d^{3} / d^{7}$ and $d^{4} / d^{6} M(I I)$ or $M($ (II) complexes, the additional electrons for the later transition metal are shown in red, and the electrons that apply to both states are shown in blue. The $d^{3}$ or $d^{7}$ complexes do not have a defined HS state. (bottom) The ten main monodentate ligands studied in this work ordered by their increasing ligand field strength, which tunes the octahedral field splitting (schematically shown at left). Atoms in the ball-and-stick representation are colored as follows: $\mathrm{H}$ in white, $\mathrm{C}$ in gray, $\mathrm{N}$ in blue, $\mathrm{O}$ in red, $\mathrm{F}$ in light blue, $\mathrm{P}$ in orange, $\mathrm{S}$ in yellow, and $\mathrm{Cl}$ in green.

(i.e., $\mathrm{Mn}(\mathrm{II}) / \mathrm{Tc}(\mathrm{II})$ or $\mathrm{Fe}(\mathrm{III}) / \mathrm{Ru}(\mathrm{III})$ ) were studied in LS doublet, IS quartet, and HS sextet states (Fig. 1). Analogously, $\mathrm{d}^{4}$ (i.e., $\mathrm{Mn}(\mathrm{III}) / \mathrm{Tc}(\mathrm{III})$ or $\mathrm{Cr}(\mathrm{II}) / \mathrm{Mo}(\mathrm{II}))$ and $\mathrm{d}^{6}$ (i.e., $\mathrm{Fe}(\mathrm{II}) / \mathrm{Ru}(\mathrm{II})$ or $\mathrm{Co}(\mathrm{III}) /$ $\mathrm{Rh}(\mathrm{III})$ ) metals were calculated in LS singlet, IS triplet, and HS quintet states (Fig. 1).

We calculated properties of complexes formed from combinations of ten small, monodentate ligands that spanned ligand field strengths and coordinating element identities. Negatively charged halides $\left(\mathrm{Cl}^{-}\right.$and $\left.\mathrm{F}^{-}\right)$ions are known ${ }^{140}$ to have among the weakest field strengths, while several others (i.e., phosphine, carbonyl, and cyanide) have among the highest field strengths (Fig. 1). Intermediate behavior is expected of the remaining (i.e., water, ammonia, hydrogen sulfide, acetonitrile, and methyl isocyanide) ligands (Fig. 1). In addition to homoleptic complexes, heteroleptic complexes were formed from up to two ligands (i.e., $\mathrm{L}_{1}$ and $\left.\mathrm{L}_{2}\right)$. Both $\mathrm{M}\left(\mathrm{L}_{1}\right)_{4}\left(\mathrm{~L}_{2}\right)_{2}$ TMCs with the two minority $\mathrm{L}_{2}$ ligands either trans (i.e., aligned $180^{\circ}$ in the TMC) or cis (i.e., $90^{\circ}$ in the TMC) were studied along with $\mathrm{M}\left(\mathrm{L}_{1}\right)_{5}\left(\mathrm{~L}_{2}\right)$ TMCs.

\section{b. Electronic structure calculations}

Calculations on mononuclear, octahedral TMCs studied in this work followed an established protocol. ${ }^{141,142}$ All initial structures were generated using molSimplify, ${ }^{48,143,144}$ which employs OpenBabel $^{145,146}$ as a backend for ligand structure generation. These calculations were automated and checked for fidelity with molSimplify automatic design (mAD). ${ }^{119,141}$ All TMCs were geometry optimized with DFT using a development version of TeraChem. ${ }^{147,148}$ For the geometry optimizations, the standard B3LYP ${ }^{149-151}$ global hybrid functional was employed along with modified forms in which the Hartree-Fock exchange fraction $\left(a_{\mathrm{HF}}\right)$ was varied from its default value of 0.20 to as low as
$a_{\mathrm{HF}}=0.00$ (i.e., a pure BLYP GGA) or as high as $a_{\mathrm{HF}}=0.30$ in increments of 0.05 while holding the LDA/GGA exchange ratio fixed. ${ }^{37,136}$ As in $3 \mathrm{~d}$ TMCs, ${ }^{37,39,40}$ sensitivities from $a_{\mathrm{HF}}$ variations using PBE as the GGA xc functional are comparable on a representative $4 \mathrm{~d}$ TMC (ESI, $\dagger$ Table S1). All calculations employed the LANL2DZ ${ }^{152}$ effective core potential for transition metals and the $6-31 G^{*}$ basis for all other atoms. Only singlet calculations were carried out in a spin-restricted formalism, with all other spin multiplicities carried out unrestricted. Level shifting $^{153}$ was employed to aid self-consistent field (SCF) convergence with the majority spin and minority spin virtual orbitals each shifted by $0.25 \mathrm{Ha}$. The default SCF convergence threshold of $3 \times 10^{-5}$ for the largest component of the DIIS vector was employed. Geometry optimizations were carried out in translation rotation internal coordinates ${ }^{154}$ using the L-BFGS algorithm to default tolerances for the gradient of $4.5 \times$ $10^{-4}$ Hartree Bohr $^{-1}$ and energy difference between steps of $10^{-6}$ Hartree. Geometric properties from a representative case optimized with a larger triple- $\zeta$ basis set and the resulting exchange sensitivities preserves trends (ESI, $\dagger$ Table S1).

For the mAD calculation workflow, calculations were run for 24-hour increments and resubmitted for up to five additional runs. At each resubmission, mAD applies loose geometric criteria $^{141}$ and abandons any calculations that fail these checks (ESI, $\dagger$ Table S2). In this workflow, the B3LYP $\left(a_{\mathrm{HF}}=0.20\right)$ geometry optimization was carried out first. If the B3LYP geometry optimization converged, we used the converged structure and wavefunction to initialize geometry at the adjacent increased (i.e., 0.25) and decreased (i.e., 0.15) $a_{\mathrm{HF}}$ values, as in prior work. ${ }^{136}$ If these calculations converged, their structures and wavefunctions were then used for the next adjacent (e.g., increased to 0.30 or decreased to 0.10$) a_{\mathrm{HF}}$ value geometry optimizations. However, if an optimization failed to converge, the next $a_{\mathrm{HF}}$ value was not attempted.

For all converged calculations, automated data fidelity checks were employed based on refinements of prior geometric ${ }^{141}$ and electronic structure criteria ${ }^{141,142,155}$ (ESI, † Table S2). Specifically, complexes were retained if their structure was deemed to be intact based on tighter geometric criteria than were employed during the optimization (ESI, $\dagger$ Table S3). The electronic structure criteria required that the deviation of the $\hat{S}^{2}$ expectation value from its anticipated value (i.e., $S(S+1)$ ) was below 1 and the Mulliken metal atomic spin density was within $1 \mu_{\mathrm{B}}$ of the total spin of the molecule (ESI, $\dagger$ Table S3).

Linearized exchange sensitivities, $S$, were obtained from linear fits of the dependence of the relevant property (e.g., $\Delta E_{\mathrm{H}-\mathrm{L}}$ ) on $a_{\mathrm{HF}}$. The resulting sensitivity $\left(e . g\right.$.,$\left.S\left(\Delta E_{\mathrm{H}-\mathrm{L}}\right)\right)$ is reported as the change in property over the range from $a_{\mathrm{HF}}=0.0$ to 1.0 , which we refer to as HFX as in prior work. ${ }^{29,37,136}$ As long as a single, qualitatively consistent electronic state has been converged over all points, this linear approximation is known to be good for a range of properties, both energetic (e.g., spin splitting ${ }^{29,35-37,131,136}$ and reaction energies $\left.{ }^{29,156}\right)$ and electronic ${ }^{30,31,157}$ in nature. To ensure that linearized exchange sensitivities could be quantitatively obtained from collected data points, we applied a series of constraints and filtering steps; this procedure and its results are 
detailed in ESI, $\uparrow$ Table S4. All raw data, resulting $R^{2}$ values, computed sensitivities, and reasons for eliminating points or sensitivities are provided in the ESI. $\dagger$

Potential energy curves (PECs) of $3 \mathrm{~d}$ Fe(II) and $4 \mathrm{~d} \mathrm{Ru(II)}$ in LS singlet and HS quintet states were obtained for homoleptic complexes of $\mathrm{He}$ atoms and $\mathrm{CO}$ ligands also using TeraChem and B3LYP/LACVP* with modified $a_{\mathrm{HF}}$ values. These PECs were obtained by rigidly shifting all six $\mathrm{He}$ atom (CO) ligands from distances as short as $1.70 \AA$ (1.80 $\mathrm{\AA})$ to as long as $2.90 \AA$ (2.80 $)$ in $0.01 \AA(0.02 \AA)$ increments, with calculations at longer bond lengths starting from the converged wavefunction at the shorter bond lengths. The He atom was selected following recent work ${ }^{43}$ that showed it is a representative weak field ligand, and a single $\mathrm{He}$ atom is simpler to translate during PEC evaluation than a typical non-linear weak-field ligand (i.e., $\mathrm{H}_{2} \mathrm{O}$ or $\mathrm{NH}_{3}$ ). The $\mathrm{CO}$ bond length was fixed to $1.125 \AA$, its value in relaxed TMCs. These calculations were repeated for $a_{\mathrm{HF}}$ fractions increasing from 0.0 to 0.45 in increments of 0.05 , with wavefunctions always initializing from shorter bond lengths and lower $a_{\mathrm{HF}}$ values. All total energies and computed sensitivities are provided in the ESI. $\dagger$

\section{Results and discussion}

\section{a. Ligand field sensitivity trends in homoleptic TMCs}

To understand the extent to which previous observations $^{35-38,40,126,131}$ in first-row transition metals are likely to be generalizable to the second row, we first compared spinsplitting properties for a subset of homoleptic complexes. Depending on the field strength of the ligand, 3d Fe(II) TMCs are known to favor distinct ground states. ${ }^{140}$ For example, $\mathrm{d}^{6}$ Fe(II) TMCs with intermediate-field nitrogen-coordinating ligands commonly exhibit spin crossover (SCO) ${ }^{158}$ phenomena by changing from an LS singlet to HS quintet state with increasing temperature. The $\Delta E_{\mathrm{H}-\mathrm{L}}$ for these complexes is sensitive to $\mathrm{HF}$ exchange fraction, becoming more negative with increasing $a_{\mathrm{HF}}$. The combination of this physical phenomenon with sensitivity to DFT functional parameters means that different $a_{\mathrm{HF}}$ values can predict the same complex to have either an LS or HS ground state. ${ }^{35-38,40,126,131}$

Indeed, for the complexes studied in this work, homoleptic complexes of $\mathrm{Fe}(\mathrm{II})$ with acetonitrile or cyanide have neardegenerate LS and HS states when evaluated with B3LYP and thus are predicted to be LS with lower HF exchange (i.e., $a_{\mathrm{HF}}=0.1$ ) but HS with higher fractions (i.e., $a_{\mathrm{HF}}=0.3$, Fig. 2). Consistent with prior observations, ${ }^{36,37,136}$ the magnitude of this typically negative exchange sensitivity, $S$, generally increases with field strength. This means that a hexa-carbonyl Fe(II) complex that is strongly LS with B3LYP can become HS with higher exchange fractions ( $c a . a_{\mathrm{HF}}=0.4$ ), whereas weak-field hexa-aqua $\mathrm{Fe}(\mathrm{II})$ is uniformly HS for all $a_{\mathrm{HF}}$ values (Fig. 2).

In comparison to their first-row counterparts, the isovalent 4d Ru(II) TMCs are considerably low-spin shifted, with almost all $\mathrm{Ru}(\mathrm{II})$ complexes strongly favoring LS states over HS states except for the weakest field (i.e., hexa-fluoride) cases (Fig. 2). The $\mathrm{Ru}(\mathrm{II})$ homoleptic complexes also exhibit uniformly reduced

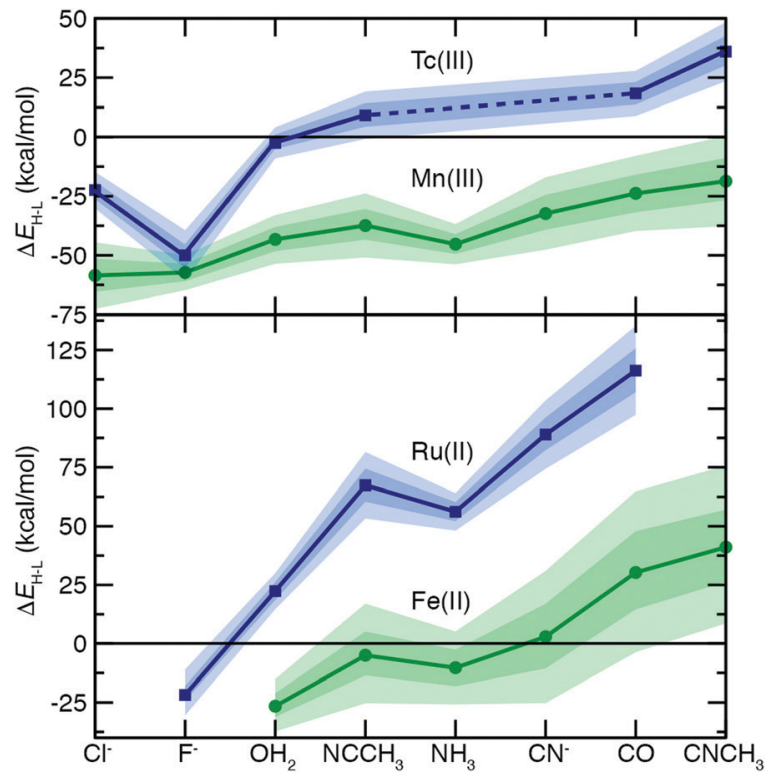

Fig. 2 The HS-LS adiabatic spin splitting $\left(\Delta E_{\mathrm{H}-\mathrm{L}}\right.$, in $\left.\mathrm{kcal} \mathrm{mol}^{-1}\right)$ for isovalent $3 d$ (in green) and $4 d$ (in blue) homoleptic TMCs: Tc(II) and $\mathrm{Mn}($ II) (top) or Fe(॥) and Ru(॥) (bottom). Ligands have been ordered on the $x$-axis roughly according to ligand field strength with the metalcoordinating atom listed first in the chemical name. The points (circles for $3 \mathrm{~d}$, squares for $4 \mathrm{~d}$ ) correspond to values at $a_{\mathrm{HF}}=0.2$, the inner translucent shaded regions correspond to the $a_{\mathrm{HF}}=0.1-0.3$ range, and the outer translucent shaded regions correspond to $a_{\mathrm{HF}}=0.0-0.4$. A zero axis is shown to indicate where spin state ordering changes between HS and LS states. A dashed line for TC(III) indicates that no data is available for $\mathrm{NH}_{3}$ and $\mathrm{CN}^{-}$complexes.

exchange sensitivities (Fig. 2). Thus, complexes with modest B3LYP $\Delta E_{\mathrm{H}-\mathrm{L}}$ values (e.g., hexa-aqua $\mathrm{Ru}(\mathrm{II})$, ca. $25 \mathrm{kcal} \mathrm{mol}^{-1}$ ) are not predicted to change their ground state with varied $a_{\mathrm{HF}}$ in contrast to Fe(II) homoleptic complexes (Fig. 2). Despite these differences, qualitative trends with ligand field strength appear preserved from $\mathrm{Fe}$ (II) to $\mathrm{Ru}(\mathrm{II})$, with increasing exchange sensitivity apparent with increasing ligand field (Fig. 2).

Given the strong LS shift of $4 \mathrm{~d} \mathrm{Ru}(\mathrm{II})$ TMCs with respect to their 3d Fe(II) TMC counterparts, we identified $d^{4} \mathrm{Tc}(\mathrm{III})$ as a possible metal/oxidation state where TMCs could be expected to favor HS or LS states depending on field strength (Fig. 2). The $4 \mathrm{~d}$ Tc(III) singlet LS and quintet HS states are in fact close in energy with B3LYP for weak-field (i.e., hexa-aqua) and intermediate-field (i.e., hexa-acetonitrile) complexes (Fig. 2). The isovalent Mn(III) complexes are comparatively HS shifted, with only the homoleptic methyl-isocyanide with a pure BLYP (i.e., $a_{\mathrm{HF}}=0.0$ ) GGA coming close to spanning the LS-HS transition (Fig. 2). The exchange sensitivity of all Mn(III) homoleptic TMCs is reduced with respect to the Fe(II) TMCs but follows a consistent trend of increasing with increasing ligand field strength (Fig. 2). Consistent with $3 \mathrm{~d} / 4 \mathrm{~d}$ observations from $\mathrm{Fe}(\mathrm{II}) / \mathrm{Ru}(\mathrm{II}), \mathrm{Tc}(\mathrm{III})$ homoleptic TMCs have reduced exchange sensitivity compared to isovalent Mn(III) (Fig. 2). This means that even though a number of $4 \mathrm{~d}$ Tc(III) TMCs have modest B3LYP $\Delta E_{\mathrm{H}-\mathrm{L}}\left(<25 \mathrm{kcal} \mathrm{mol}^{-1}\right)$ values, the only ground state assignment change for $\mathrm{Tc}(\mathrm{III})$ in this series would be for the 
B3LYP HS hexa-aqua complex to become LS when $a_{\mathrm{HF}}$ is 0.1 or less (Fig. 2). Overall, reduced exchange sensitivities in these $4 \mathrm{~d}$ TMCs (i.e., whether with $\mathrm{Ru}(\mathrm{II})$ or $\mathrm{Tc}(\mathrm{III})$ ) would require the

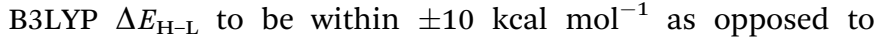
$\pm 25 \mathrm{kcal} \mathrm{mol}^{-1}$ for comparable $3 \mathrm{~d}$ TMCs for the $4 \mathrm{~d}$ TMC spin-state preference to change with HF exchange.

Both $\mathrm{d}^{6} \mathrm{Fe}(\mathrm{II}) / \mathrm{Ru}(\mathrm{II})$ and $\mathrm{d}^{4} \mathrm{Mn}(\mathrm{III}) / \mathrm{Tc}(\mathrm{III}) \mathrm{TMCs}$ have an IS triplet state. We thus also calculated the IS state to obtain $\Delta E_{\mathrm{H}-\mathrm{I}}$ and $\Delta E_{\mathrm{I}-\mathrm{L}}$ as well as their sensitivities (i.e., $S\left(\Delta E_{\mathrm{H}-\mathrm{I}}\right)$ and $\left.S\left(\Delta E_{\mathrm{I}-\mathrm{L}}\right)\right)$ for select homoleptic TMCs. We identified hexacarbonyl TMCs as representative strong-field complexes and hexa-aqua as representative weak-field complexes (Fig. 3). All 4d TMCs favor IS states over HS states with B3LYP (i.e., $\Delta E_{\mathrm{H}-\mathrm{I}}>0$ ) unlike the isovalent $3 \mathrm{~d}$ TMCs (Fig. 3). Spin-state orderings change with $a_{\mathrm{HF}}$ due to high $S$ for several of the 3d TMCs (i.e., HS-IS/HS-LS

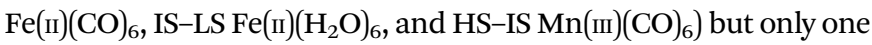
of the $4 \mathrm{~d}$ TMCs (i.e., HS-LS Tc(III) $\left.\left(\mathrm{H}_{2} \mathrm{O}\right)_{6}\right)$ in part due to the reduced exchange sensitivity of 4d TMCs (Fig. 3 ).

For all spin-splitting energies, the hexa-aqua exchange sensitivities are lower than those for hexa-carbonyl in both $3 \mathrm{~d}$ and 4d TMCs (Fig. 3). As can be expected, ${ }^{39,40} S\left(\Delta E_{\mathrm{H}-\mathrm{I}}\right)$ and $S\left(\Delta E_{\mathrm{I}-\mathrm{L}}\right)$ are reduced with respect to $S\left(\Delta E_{\mathrm{H}-\mathrm{L}}\right)$, with $S\left(\Delta E_{\mathrm{I}-\mathrm{L}}\right)$ consistently the smallest of the three (Fig. 3 ). The trend holds across the over 150 pairs of $3 \mathrm{~d} / 4 \mathrm{~d}$ heteroleptic or homoleptic TMCs for which all three spin-state energies have been evaluated. On average, $S\left(\Delta E_{\mathrm{I}-\mathrm{L}}\right)$ and $S\left(\Delta E_{\mathrm{H}-\mathrm{I}}\right)$ values are $38 \%$ and $62 \%$ of $S\left(\Delta E_{\mathrm{H}-\mathrm{L}}\right)$, respectively (ESI, $\dagger$ Table S5). That is, when the $4 \mathrm{~d}$ TMC $S$ value is reduced with respect to its $3 \mathrm{~d}$ TMC counterpart, this reduction is proportional across both spin states and ligand chemistry.

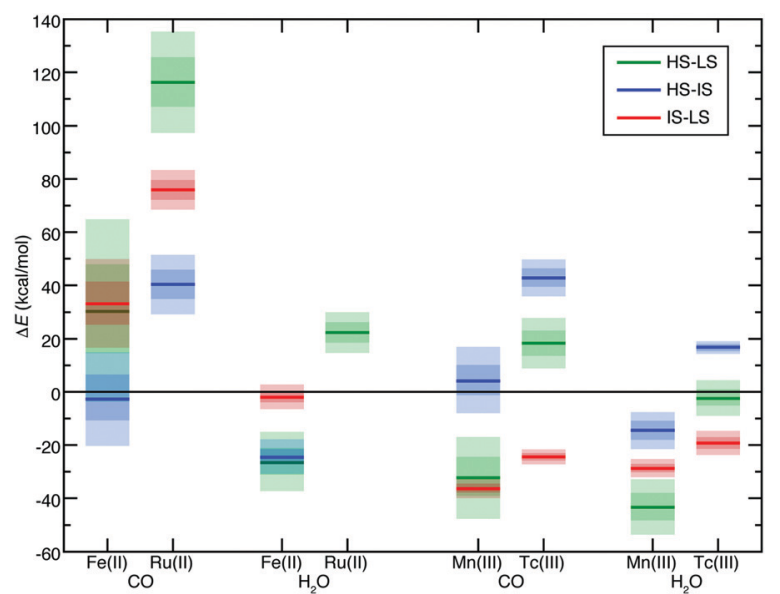

Fig. 3 Comparisons of adiabatic spin splitting $\left(\Delta E\right.$, in $\left.\mathrm{kcal} \mathrm{mol}^{-1}\right)$ for HS-LS (green lines and shading), HS-IS (blue lines and shading) and IS-LS (red lines and shading) for pairs of homoleptic TMCs grouped first

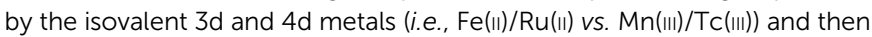
by ligand (i.e., $\mathrm{CO}$ vs. $\mathrm{H}_{2} \mathrm{O}$ ), as indicated on the $x$-axis. The solid lines correspond to values at $a_{\mathrm{HF}}=0.2$, the inner translucent shaded regions correspond to the $a_{\mathrm{HF}}=0.1-0.3$ range, and the outer translucent shaded regions correspond to $a_{\mathrm{HF}}=0.0-0.4$. A zero axis is shown to indicate where ordering changes for any pair of states. The $\mathrm{Ru}(\|)\left(\mathrm{H}_{2} \mathrm{O}\right)_{6}$ IS state was eliminated during filtering steps, and so its HS-IS or IS-LS data is unavailable.

\section{b. Global comparison of $3 \mathrm{~d}$ and $4 \mathrm{~d}$ TMCs}

We next expanded our comparison of HS-LS energies and their sensitivities to include heteroleptic complexes for an overall set of more than $200 \mathrm{~d}^{4}-\mathrm{d}^{6}$ TMC pairs. Over all of these $3 \mathrm{~d} / 4 \mathrm{~d}$ TMC pairs, the $4 \mathrm{~d} S\left(\Delta E_{\mathrm{H}-\mathrm{L}}\right)$ was consistently reduced with respect to that for 3d TMCs (Fig. 4). The largest (i.e., most negative) 3d $S\left(\Delta E_{\mathrm{H}-\mathrm{L}}\right)$ values are larger than those of $4 \mathrm{~d}$ TMCs by around $50 \mathrm{kcal} \mathrm{mol}^{-1} \mathrm{HFX}^{-1}$ (i.e., around 40\% larger, ESI, $\dagger$ Table S6). For each 3d metal/oxidation state, average exchange sensitivities also vary, i.e., highest for $\mathrm{Mn}$ (II) or $\mathrm{Fe}(\mathrm{II})$ and lowest for $\mathrm{Cr}(\mathrm{II})$, with similar trends for the isovalent $4 \mathrm{~d}$ metal/oxidation states (ESI, $\dagger$ Table S6). The overall reduced sensitivities of $4 \mathrm{~d}$ TMCs become more apparent the larger the $3 \mathrm{~d}$ TMC $S$ values are (Fig. 4). Based on prior analysis ${ }^{36,37,136}$ and our observations on homoleptics, this should mean that strong-field 3d TMCs are much more sensitive to HF exchange than 4d TMCs while weak-field 3d and 4d TMCs complexes have more similar exchange sensitivity (Fig. 4). Indeed, the sensitivities of the prototypical strong-field hexa-carbonyl and weak-field hexaaqua homoleptics largely reside at extremes of the overall relationship between 3d and 4d TMC $S$ values (Fig. 4).

There are a few noteworthy exceptions where the $4 \mathrm{~d}$ TMC $S$ exceeds that of its $3 \mathrm{~d}$ TMC counterpart, namely: (i) in weakfield, hexafluoro complexes of $\mathrm{Mn}$ (III)/Tc(III) $(S(3 \mathrm{~d}) c a$. $-35 v s$. $S(4 \mathrm{~d})-50$ to $-70 \mathrm{kcal} \mathrm{mol}^{-1} \mathrm{HFX}^{-1}$ ) and (ii) in stronger fields (e.g., $\left.\mathrm{Mn}(\mathrm{II})\left(\mathrm{NCCH}_{3}\right)_{4}\left(\mathrm{CNCH}_{3}\right)_{2}\right)$ where the $3 \mathrm{~d}$ TMC sensitivity is typical but the $\mathrm{Tc}(\mathrm{II})$ value is among the largest evaluated for $4 \mathrm{~d}$ TMCs (ESI, $\dagger$ Table S7). The strong net negative charge on the halide complexes also results in other types of outliers: $\mathrm{Ru}(\mathrm{III})$ hexafluoride and $\mathrm{a} \mathrm{Cl}^{-}$-containing $\mathrm{Mo}(\mathrm{II})$ complex are the only two 4d TMC cases for which the $S\left(\Delta E_{\mathrm{H}-\mathrm{L}}\right)$ is weakly (ca. 20-45 kcal mol ${ }^{-1} \mathrm{HFX}^{-1}$ ) positive (ESI, $\uparrow$ Table S8). In both $4 \mathrm{~d}$

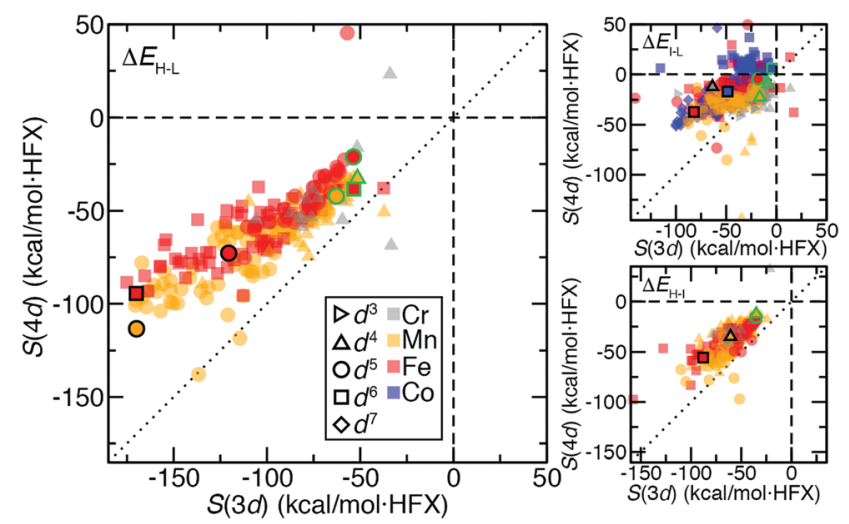

Fig. 4 Sensitivities, $S$, of $3 d$ vs. 4d ligand-matched TMCs (in kcal mol ${ }^{-1}$ $\mathrm{HFX}^{-1}$ ) for $\Delta E_{\mathrm{H}-\mathrm{L}}$ (left), $\Delta E_{\mathrm{I}-\mathrm{L}}$ (top, right), and $\Delta E_{\mathrm{H}-\mathrm{I}}$ (bottom, right). Translucent symbols are colored by element: $\mathrm{Cr}$ in gray, $\mathrm{Mn}$ in orange, Fe in red, and Co in blue. The formal electron configuration of each point is indicated by the symbol shape: $d^{3}$ right-pointing triangles, $d^{4}$ up-pointing triangles, $d^{5}$ circles, $d^{6}$ squares, and $d^{7}$ diamonds. The $d^{3}$ and $d^{7}$ data is only available for $\Delta E_{1-L}$. All hexa-aqua complexes are filled solid and outlined in green, and all hexa-carbonyl complexes are filled solid and outlined in black. The zero axis for both sensitivities is shown as a dashed black line, and a black dotted parity line is also shown. 
TMCs, the corresponding $3 \mathrm{~d}$ TMC still has a negative, albeit small $S$ value (ESI, $\dagger$ Table S8).

Trends for the 2-electron $\Delta E_{\mathrm{H}-\mathrm{I}}$ are largely consistent with those for the 4-electron $\Delta E_{\mathrm{H}-\mathrm{L}}$. Although overall $S\left(\Delta E_{\mathrm{H}-\mathrm{I}}\right)$ values for both $3 \mathrm{~d}$ and $4 \mathrm{~d}$ TMCs are lower than $S\left(\Delta E_{\mathrm{H}-\mathrm{L}}\right), 3 \mathrm{~d}$ TMC sensitivities nearly always exceed their $4 \mathrm{~d}$ TMC values (Fig. 4 and ESI, $\uparrow$ Table S6). The $3 \mathrm{~d} / 4 \mathrm{~d}$ metal/oxidation states with the highest average $S\left(\Delta E_{\mathrm{H}-\mathrm{L}}\right)$ (i.e., $\mathrm{Mn}(\mathrm{II}) / \mathrm{Tc}(\mathrm{II})$ and $\left.\mathrm{Fe}(\mathrm{II}) / \mathrm{Ru}(\mathrm{II})\right)$ also have the highest $S\left(\Delta E_{\mathrm{H}-\mathrm{I}}\right)$ values (ESI, $\dagger$ Table S6). On average, best-fit lines relating $S(4 \mathrm{~d}) v s$. $S(3 \mathrm{~d})$ for $\Delta E_{\mathrm{H}-\mathrm{L}}$ and $\Delta E_{\mathrm{H}-\mathrm{I}}$ have comparable ratios of change in $S(4 \mathrm{~d})$ per change in $S(3 \mathrm{~d})$ of 0.55 and 0.65 , respectively (ESI, $\dagger$ Table S6). As in the case of $\Delta E_{\mathrm{H}-\mathrm{L}}$, a small number of $4 \mathrm{~d}$ TMC $\Delta E_{\mathrm{H}-\mathrm{I}}$ sensitivities exceed their $3 \mathrm{~d}$ TMC counterparts and typically correspond to Mn(II) complexes with strong-field equatorial ligands $\left(\mathrm{CO}\right.$ or $\left.\mathrm{NCCH}_{3}\right)$ expected to have strong Jahn-Teller distortion (ESI, $†$ Table S7).

We also analyzed 2-electron $\Delta E_{\text {I-L }}$ pair trends, which additionally include $\mathrm{d}^{3} \mathrm{Cr}$ (III)/Mo(III) and $\mathrm{d}^{7} \mathrm{Co}$ (II)/ $/ \mathrm{Rh}$ (II) TMCs in their doublet LS and quartet IS states (see Fig. 1). As in the other two cases of spin-splitting energetics, $4 \mathrm{~d}$ TMCs exhibit reduced exchange sensitivity with respect to $3 \mathrm{~d}$ TMCs (Fig. 4 and ESI, $\dagger$ Table S6). For the $\mathrm{d}^{3} / \mathrm{d}^{7}$ TMCs for which only $\Delta E_{\mathrm{I}-\mathrm{L}}$ is defined, $S(4 \mathrm{~d}): S(3 \mathrm{~d})$ ratios from best-fit lines of 0.42 for $\mathrm{d}^{3}$ and 0.64 for $\mathrm{d}^{7}$ are consistent with the ratios observed in $\mathrm{d}^{4}-\mathrm{d}^{6}$ TMCs (ESI, $\dagger$ Table S6). Several more $4 \mathrm{~d}$ TMC outliers that are close to parity are observed, typically $\mathrm{Mn}(\mathrm{III}) / \mathrm{Tc}$ (III) complexes with equatorial chlorides or $\mathrm{Cr}(\mathrm{II}) / \mathrm{Mo}$ (II) complexes with equatorial ammonia ligands (Fig. 4 and ESI, $\dagger$ Table S7). Far more positive 4d TMC sensitivities are observed for several $\mathrm{Rh}(\mathrm{III})$ complexes with a range of weak- and strong-field ligands (ESI, $\dagger$ Table S9). A handful of 3d TMCs (e.g., in Fe(II) complexes with $\mathrm{CN}^{-}$ligands) also have positive sensitivities, but the equivalent, isovalent $\mathrm{Ru}$ (II) TMCs have weakly negative sensitivities (ESI, $\dagger$ Table S9). These observations on $\Delta E_{\mathrm{I}-\mathrm{L}}$ are distinct from $\Delta E_{\mathrm{H}-\mathrm{L}}$ and $\Delta E_{\mathrm{H}-\mathrm{I}}$ where only one cis $\mathrm{Mo}(\mathrm{II})\left(\mathrm{NH}_{3}\right)_{4}\left(\mathrm{Cl}^{-}\right)_{2}$ complex had positive $4 \mathrm{~d}$ TMC sensitivities for both quantities (ESI, $\uparrow$ Table S8).

\section{c. Analysis of a heteroleptic complex series}

Given the diversity of TMC chemistry in these larger data sets, we simplified our analysis to understand the extent to which trends in $\Delta E$ and $S(\Delta E)$ were additive in a narrower subset of representative $3 \mathrm{~d}$ and $4 \mathrm{~d}$ TMC complexes. To assess the additive nature of ligand contributions, we chose a subset of the data consisting of homoleptic complexes of a weak-field ligand $\left(\mathrm{H}_{2} \mathrm{O}\right)$, the homoleptic complexes of a strong-field ligand $(\mathrm{CO})$, and the heteroleptic complexes with both ligands present. In addition to their differing field strengths, $\mathrm{H}_{2} \mathrm{O}$ and $\mathrm{CO}$ were chosen for their neutral charge, eliminating the need to compare TMCs of differing net charge. For a fixed metal, oxidation state, and principal quantum number, the full set can contain up to six mixed $\mathrm{H}_{2} \mathrm{O} / \mathrm{CO}$ complexes between the homoleptic hexa-aqua and hexa-carbonyl limits. This includes two cases where a single ligand of the minority type is in the complex (i.e., $5+1:(\mathrm{CO})_{5}\left(\mathrm{H}_{2} \mathrm{O}\right)$ or $\left.\left(\mathrm{H}_{2} \mathrm{O}\right)_{5}(\mathrm{CO})\right)$ as well as four cases where two ligands of the alternate type are included in either a cis (i.e., equatorial/axial adjacent) or trans (i.e., axial) conformation (e.g., $(\mathrm{CO})_{4}\left(\mathrm{H}_{2} \mathrm{O}\right)_{2}$ or $\left.\left(\mathrm{H}_{2} \mathrm{O}\right)_{4}(\mathrm{CO})_{2}\right)$. Although the exchange sensitivity of homoleptic $3 \mathrm{~d}$ TMCs has been widely studied, ${ }^{35-37,118,126-129}$ the expected exchange sensitivity of heteroleptic TMCs is not well established for either $3 \mathrm{~d}$ or $4 \mathrm{~d}$ TMCs.

There is a smooth, nearly monotonic increase in $\Delta E_{\mathrm{H}-\mathrm{L}}$ with increasing number of strong-field $\mathrm{CO}$ ligands for $\mathrm{Fe}(\mathrm{II})$ or $\mathrm{Ru}(\mathrm{II})$ complexes (Fig. 5). For the Fe(II) TMCs, B3LYP LS states become stabilized over HS states for four or more CO ligands, whereas all $\mathrm{Ru}(\mathrm{II})$ complexes are uniformly LS (Fig. 5). The trend of increasing $\Delta E_{\mathrm{H}-\mathrm{L}}$ with increasing $\mathrm{CO}$ number is largely consistent between $\mathrm{Ru}$ (II) and $\mathrm{Fe}(\mathrm{II})$, but B3LYP $\Delta E_{\mathrm{H}-\mathrm{L}}$ for $\mathrm{Ru}$ (II) is more sensitive to the number of $\mathrm{CO}$ ligands (Fig. 5). Interestingly, the only exception to the monotonic trend is the trans $\left(\mathrm{H}_{2} \mathrm{O}\right)_{4}(\mathrm{CO})_{2}$ isomer, with an $\Delta E_{\mathrm{H}-\mathrm{L}}$ closer to that for the mono-carbonyl complexes (Fig. 5 and ESI, $\dagger$ Tables S10, S11). The cis $\left(\mathrm{H}_{2} \mathrm{O}\right)_{2}(\mathrm{CO})_{4}$ isomer has been filtered from the dataset, prohibiting broader conclusions about cis/trans isomers (see ESI $\dagger$ ). For the Fe(II) TMCs, all mixed $\mathrm{H}_{2} \mathrm{O} / \mathrm{CO}$ complexes span the LS/HS transition between $a_{\mathrm{HF}}=0.0$ and 0.4 (Fig. 5). While Fe(II) TMC $S$ values are significantly larger than for $\mathrm{Ru}(\mathrm{II}) \mathrm{TMCs}$, both 3d and 4d complexes appear to have a monotonic increase in sensitivity with the addition of more strong-field ligands (Fig. 5 and ESI, $\uparrow$ Table S12).

For the series of $\mathrm{d}^{4} \mathrm{Mn}(\mathrm{III}) / \mathrm{Tc}(\mathrm{III}) \mathrm{TMCs}$, reduced overall ligand field dependence of both $\Delta E_{\mathrm{H}-\mathrm{L}}$ and $S$ is observed with

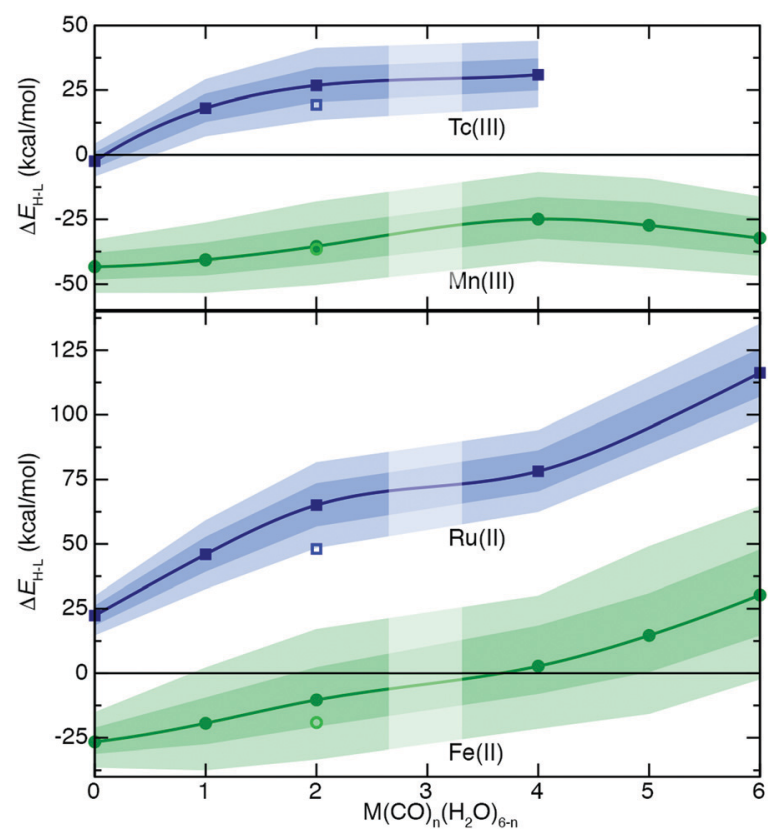

Fig. 5 Properties of complexes formed by mixing $\mathrm{H}_{2} \mathrm{O}$ and $\mathrm{CO}$ ligands. Variation of 4-electron $\Delta E_{\mathrm{H}-\mathrm{L}}$ (in kcal mol${ }^{-1}$ ) with increasing number of $\mathrm{CO}$ ligands for isovalent $\mathrm{Mn}\left({ }_{\mathrm{II}}\right) / \mathrm{Tc}(\mathrm{II})$ or $\mathrm{Fe}(॥) / \mathrm{Ru}\left({ }_{1}\right)$. The points (circles for $3 \mathrm{~d}$, squares for $4 \mathrm{~d}$ ) correspond to values at $a_{\mathrm{HF}}=0.2$, the inner translucent shaded regions correspond to the $a_{\mathrm{HF}}=0.1-0.3$ range, and the outer translucent shaded regions correspond to $a_{\mathrm{HF}}=0.0-0.4$. A zero axis is shown to indicate where spin-state ordering changes. A spline has been fit through the $a_{\mathrm{HF}}=0.2$ values excluding the open, lighter colored symbol, which corresponds to an outlier trans configuration with two CO ligands. No cis data is available for the case with four CO ligands, and no calculations were attempted for $3 \mathrm{CO}$ ligands, as indicated by vertical translucent bar. 
respect to $\mathrm{Fe}(\mathrm{II}) / \mathrm{Ru}(\mathrm{II})$ TMCs (Fig. 5 and ESI, $\dagger$ Tables S10, S12). The 3d Mn(III) TMCs are uniformly HS-favored regardless of $a_{\mathrm{HF}}$ value (Fig. 5). Both $\Delta E_{\mathrm{H}-\mathrm{L}}$ and $S$ values appear to reach a maximum for $\mathrm{Mn}$ (III) complexes once all four equatorial ligands are $\mathrm{CO}$ with no effect of added $\mathrm{CO}$ axial ligands (Fig. 5). This likely occurs both because of the reduced ligand field sensitivity of $\mathrm{Mn}$ (III) and non-monotonic geometric changes for the most CO-saturated Mn(III) complexes (see ESI $\dagger$ data). Overall trends are consistent between Tc(III) and $\mathrm{Mn}$ (III), although the $4 \mathrm{~d}$ TMCs are again marked by reduced $S$ values with respect to the isovalent 3d TMCs (Fig. 5). Given the reduced sensitivities of $4 \mathrm{~d}$ TMCs, only the homoleptic aqua Tc(III) complex spans the LS-to-HS transition, whereas even the modest $\Delta E_{\mathrm{H}-\mathrm{L}}$ $\left(<15 \mathrm{kcal} \mathrm{mol}^{-1}\right)$ in the mono-carbonyl Tc(III) complex remains LS-favored over all $a_{\mathrm{HF}}$ values (Fig. 5). Across an expanded series of TMCs with more metals (i.e., $\mathrm{d}^{5} \mathrm{Fe}(\mathrm{III}) / \mathrm{Ru}(\mathrm{III})$ and $\mathrm{Mn}(\mathrm{II}) /$ Tc(II)), addition of strong-field carbonyl ligands has a largely monotonic, linearly increasing effect on $S$ values starting from the lower extreme of homoleptic hexa-aqua TMCs and moving toward the upper extreme of hexa-carbonyl TMCs (Fig. 6 and ESI, $\dagger$ Table S12). The most significant deviations in $S$ between $3 \mathrm{~d} / 4 \mathrm{~d}$ TMC pairs occurs for the $\mathrm{Fe}(\mathrm{II}) / \mathrm{Ru}$ (II) cases (i.e., up to a $60 \mathrm{kcal} \mathrm{mol}^{-1} \mathrm{HFX}^{-1}$ difference) but remains substantial for most metals, excluding only the low- $S \mathrm{Mn}(\mathrm{III}) / \mathrm{Tc}(\mathrm{III})$ pairs (Fig. 6). Over this broad set, we confirm the cis $\left(\mathrm{H}_{2} \mathrm{O}\right)_{4}(\mathrm{CO})_{2}$ complexes have significantly higher sensitivities for both $3 \mathrm{~d}$ and $4 \mathrm{~d}$ metals than their trans counterparts, with the exception of $\mathrm{Mn}(\mathrm{III}) / \mathrm{Tc}$ (III) (Fig. 6).

We also analyzed this ligand series for $\Delta E$ and $S(\Delta E)$ trends in the 2-electron HS-IS and IS-LS spin state splitting. For $\Delta E_{\mathrm{H}-\mathrm{I}}$, increasing the number of CO ligands shifts the B3LYP preference

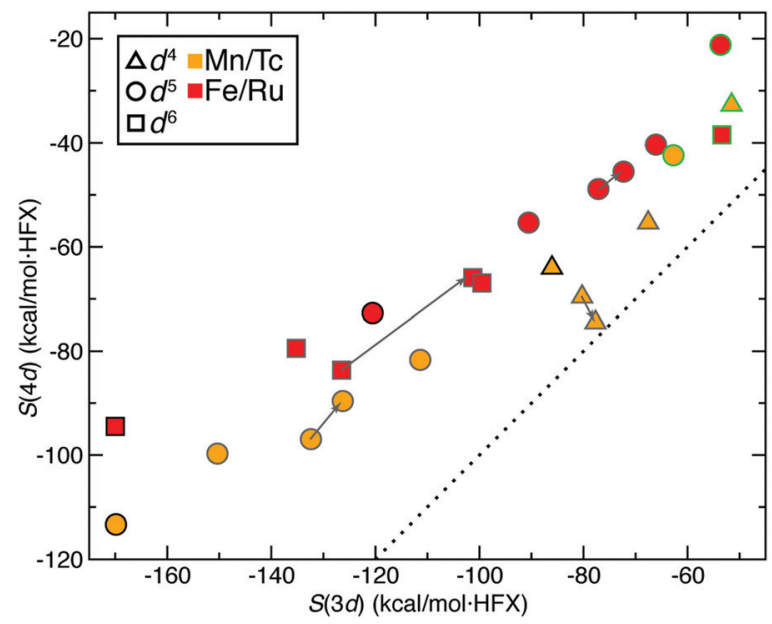

Fig. 6 Properties of complexes formed by mixing $\mathrm{H}_{2} \mathrm{O}$ and $\mathrm{CO}$ ligands. $S(3 d)$ vs. $S(4 d)$ for $\Delta E_{\mathrm{H}-\mathrm{L}}$ (in kcal mol $\mathrm{kFF}^{-1}$ ) of Mn/Tc and Fe/Ru TMCs with $\mathrm{CO}$ or $\mathrm{H}_{2} \mathrm{O}$ ligands in both oxidation states, colored by element ( $\mathrm{Mn} / \mathrm{Tc}$ in orange or $\mathrm{Fe} / \mathrm{Ru}$ in red) and with symbols corresponding to formal electron configuration $\left(d^{4}\right.$ in up triangles, $d^{5}$ in circles, and $d^{6}$ in squares). All hexa-aqua complexes are outlined in green, all hexa-carbonyl complexes are outlined in black, and the remaining symbols are outlined in dark gray. A gray arrow shows the path from each cis to trans $\left(\mathrm{H}_{2} \mathrm{O}\right)_{4}(\mathrm{CO})_{2}$ sensitivity. A dotted parity line is shown for reference. from HS to IS for most 3d metals (i.e., excluding only Mn(III) and $\mathrm{Fe}(\mathrm{II})$ ), but the $4 \mathrm{~d}$ TMC preference remains uniformly IS regardless of complex composition (ESI, $\dagger$ Tables S13 and S14). Although $S\left(\Delta E_{\mathrm{H}-\mathrm{I}}\right)$ is lower than $S\left(\Delta E_{\mathrm{H}-\mathrm{L}}\right)$, the $3 \mathrm{~d}$ TMC spin-state preference can still shift depending upon $a_{\mathrm{HF}}$ value (e.g., trans $\mathrm{Fe}(\mathrm{II})\left(\mathrm{H}_{2} \mathrm{O}\right)_{4}(\mathrm{CO})_{2}$ is IS-favoring for $a_{\mathrm{HF}}=0.15$ but HS for B3LYP, ESI, $\dagger$ Table S13). The relationships of 3d and $4 \mathrm{~d}$ TMC $S\left(\Delta E_{\mathrm{H}-\mathrm{I}}\right)$ values are similar to that for $S\left(\Delta E_{\mathrm{H}-\mathrm{L}}\right)$ : (i) the smallest and largest $S$ magnitudes are typically bounded by the homoleptic hexa-aqua and hexa-carbonyl complexes, respectively, and (ii) mixed complexes with more $\mathrm{CO}$ ligands have larger sensitivities especially in $3 \mathrm{~d}$ versus $4 \mathrm{~d}$ TMCs (ESI, $\dagger$ Fig. $\mathrm{S} 1$ and Table S15). For $\Delta E_{\mathrm{I}-\mathrm{L}}$, multiple $\mathrm{d}^{3} \mathrm{Cr}(\mathrm{III}) / \mathrm{Mo}$ (III) and $\mathrm{d}^{7} \mathrm{Co}$ (II)/ $\mathrm{Rh}$ (II) complexes could also be compared in their LS doublet and IS quartet (i.e., $l s+2)$ states (ESI, $\dagger$ Tables S16 and S17). Reduced exchange sensitivity for IS-LS pairs mean that few ground state assignments change in either $3 \mathrm{~d}$ or $4 \mathrm{~d}$ TMCs with change in functional (ESI, $\dagger$ Table S15). Across all metals, the trend of increasing deviation of $3 \mathrm{~d}$ and $4 \mathrm{~d} S$ values with increasing ligand field strength is consistent with HS-LS and HS-IS behavior for mixed-ligand complexes, but non-monotonic behavior with CO ligand number is observed and several of the $\mathrm{Rh}(\mathrm{III})$ complexes have positive $S\left(\Delta E_{\mathrm{I}-\mathrm{L}}\right)$ values (ESI, $\dagger$ Fig. S2). The $S$ values are also relatively comparable and modest for early $\mathrm{d}^{3}$ $\mathrm{Cr}(\mathrm{III}) / \mathrm{Mo}(\mathrm{III})$ and $\mathrm{d}^{4} \mathrm{Mn}(\mathrm{III}) / \mathrm{Tc}(\mathrm{III})$ complexes (ESI, $\dagger$ Fig. S2).

As a possible explanation for the distinct behavior of IS-LS spin splitting trends among complexes, we considered differences in closed-shell LS states (i.e., for $\mathrm{d}^{4}$ and $\mathrm{d}^{6}$ ) and open-shell ones (i.e., for $\mathrm{d}^{5}$ ) but observe no significant difference (ESI, $\dagger$ Fig. S2). The greater variability is likely due to noise in evaluating the lower IS-LS $S$ values, in line with prior observations, ${ }^{29,136}$ and the larger range of metals and oxidation states. Despite some differences for IS-LS in comparison to HS-IS or HS-LS spin-splitting energies, the ligand series analysis suggests overall that there are consistently greater differences in the effect of exchange on $3 \mathrm{~d}$ compared to $4 \mathrm{~d}$ TMCs that grow with ligand field strength.

\section{d. Effect of exchange on spin-state ordering}

TMC spin-state splitting sensitivities depend both on row (3d vs. 4d) and electron configuration (e.g., $\left.\mathrm{d}^{4} v s . \mathrm{d}^{6}\right)$ of the metal atom as well as on the strength of the ligand field. The combined effect of these differences can be further understood by evaluating how the distribution of $\Delta E_{\mathrm{H}-\mathrm{L}}$ shifts with $\mathrm{HF}$ exchange fraction. For this comparison, we chose $64 \mathrm{Fe}(\mathrm{II}) / \mathrm{Ru}(\mathrm{II})$ and $51 \mathrm{Tc}(\mathrm{III}) / \mathrm{Mn}$ (III) metal/oxidation state pairs where $3 \mathrm{~d}$ TMCs and 4d TMCs span the HS-LS transition, respectively (Fig. 7). For Fe(II) TMCs, increasing HF exchange from a pure GGA to $30 \%$ has a strong effect on the distribution of $\Delta E_{\mathrm{H}-\mathrm{L}}$ values (Fig. 7). Because complexes with strong-field ligands have more negative sensitivities than complexes with weak-field ligands, the width of the $\mathrm{Fe}(\mathrm{II}) \Delta E_{\mathrm{H}-\mathrm{L}}$ distribution decreases monotonically from $a_{\mathrm{HF}}=0.0\left(-75\right.$ to $\left.80 \mathrm{kcal} \mathrm{mol}^{-1}\right)$ to $a_{\mathrm{HF}}=0.3(-90$ to $30 \mathrm{kcal} \mathrm{mol}^{-1}$, Fig. 7). We note that a complex with $\left|\Delta E_{\mathrm{H}-\mathrm{L}}\right| \leq$ $5 \mathrm{kcal} \mathrm{mol}^{-1}$ could be a spin crossover (SCO) complex. Using this definition, the number of potential Fe(II) SCOs is maximal for moderate, $a_{\mathrm{HF}}=0.1-0.2$ exchange and decreases again at 

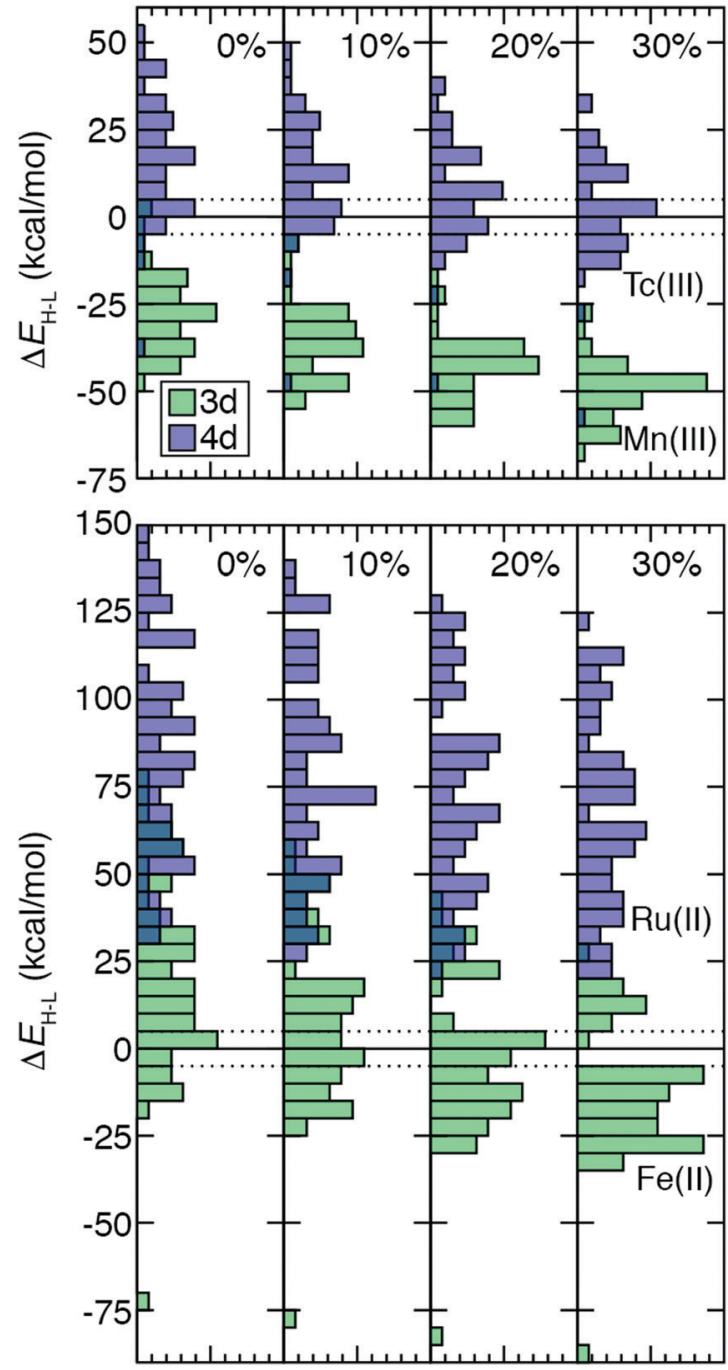

Fig. 7 Normalized histograms of $\Delta E_{\mathrm{H}-\mathrm{L}}$ (in $\mathrm{kcal} \mathrm{mol}^{-1}$ ) (bin width: $5 \mathrm{kcal} \mathrm{mol}^{-1}$ ) for 51 pairs of $3 \mathrm{~d} \mathrm{Mn(III)}$ and $4 \mathrm{~d}$ Tc(III) TMCs (top) and 64 pairs of $3 d \mathrm{Fe}(I)$ and $4 \mathrm{~d}$ Ru(II) TMCs (bottom). Histograms are filled translucent for $3 d$ (green) and $4 d$ (dark blue) TMCs to show regions of overlap. A zero line is indicated as black solid where HS-LS spin state ordering changes, and a range of $5 \mathrm{kcal} \mathrm{mol}^{-1}$ around that line is indicated with black dotted lines. The panes correspond to increasing \% HF exchange from left to right, as labeled in top inset.

higher exchange values (Fig. 7). From $a_{\mathrm{HF}}=0.0$ to 0.3 , the population of HS-favored Fe(II) TMCs also increases dramatically from 12 to 49 of 64 complexes (Fig. 7 and ESI, $\dagger$ Table S18).

The isovalent $\mathrm{Ru}$ (II) TMCs span nearly as wide a range for $a_{\mathrm{HF}}=0.0$ (30 to $150 \mathrm{kcal} \mathrm{mol}^{-1}$ ) as the $3 \mathrm{~d}$ TMCs, but none are HS at any exchange fraction (Fig. 7 and ESI, $\dagger$ Table S18). Modest differences in exchange sensitivity across $\mathrm{Ru}(\mathrm{II})$ complexes have a limited effect on the shape of the distribution in comparison to Fe(II) TMCs (Fig. 7). The range of the Ru(II) $\Delta E_{\mathrm{H}-\mathrm{L}}$ distribution for $a_{\mathrm{HF}}=0.3$ (20 to $125 \mathrm{kcal} \mathrm{mol}^{-1}$ ) is reduced, but this reduction $(12 \%)$ is smaller than was observed for the Fe(II) TMCs (19\%).

For the $\mathrm{Tc}(\mathrm{III}) / \mathrm{Mn}(\mathrm{III})$ isovalent pairs, the $4 \mathrm{~d}$ TMCs have a more even distribution of HS and LS ground states (Fig. 7).
This is particularly true ( $18 \mathrm{LS}$ and $33 \mathrm{HS}$ ) at $a_{\mathrm{HF}}=0.3$, while LS is generally favored by Tc(III) TMCs (44 LS and 7 HS) at $a_{\mathrm{HF}}=0.0$, and all $a_{\mathrm{HF}}$ values have a significant number of potential Tc(III) HS-LS SCOs (Fig. 7 and ESI, $\dagger$ Table S18). In contrast to Fe(II), most (49 of 51) Mn(III) TMCs are HS even for $a_{\mathrm{HF}}=0.0$, and all are significantly HS (i.e., outside of the SCO region) for $a_{\mathrm{HF}}=0.1$ and higher (Fig. 7 and ESI, $\dagger$ Table S18). The Mn(III) $\Delta E_{\mathrm{H}-\mathrm{L}}$ values span a smaller range than the $\mathrm{Fe}(\mathrm{II}) \mathrm{TMCs}$, meaning that even though the width of the $\mathrm{Mn}$ (III) $\Delta E_{\mathrm{H}-\mathrm{L}}$ distribution narrows only slightly with increasing $\mathrm{HF}$ exchange $\left(a_{\mathrm{HF}}=0.0:-50\right.$ to $5 \mathrm{kcal} \mathrm{mol}^{-1}$ vs. $a_{\mathrm{HF}}=0.3:-25$ to $-70 \mathrm{kcal} \mathrm{mol}^{-1}$ ), this $18 \%$ reduction is roughly comparable to that for $\mathrm{Fe}(\mathrm{II})$ (Fig. 7). For the Tc(III) $\Delta E_{\mathrm{H}-\mathrm{L}}$ distribution, there is no change in the width due to sensitivities of outliers in the distribution tails (Fig. 7). Nevertheless, both Tc(III) and Mn(III) distributions become more peaked at intermediate values of the $\Delta E_{\mathrm{H}-\mathrm{L}}$ range, and the effect of $a_{\mathrm{HF}}$ on the shape of both distributions is more modest than for Fe(II) but more significant than for Ru(II) TMCs (Fig. 7).

Over all $3 \mathrm{~d} / 4 \mathrm{~d}$ metal/oxidation state pairs for which $\Delta E_{\mathrm{H}-\mathrm{L}}$ was calculated, trends are similar to those observed for $\mathrm{Fe}(\mathrm{II}) / \mathrm{Ru}(\mathrm{II})$ and $\mathrm{Tc}(\mathrm{III}) / \mathrm{Mn}(\mathrm{III})$ (ESI, $\dagger$ Table S18). The HS-LS preference of $3 \mathrm{~d}$ TMCs is highly sensitive to exchange, with an even number of LS-favoring $v s$. HS-favoring 3d TMCs at $a_{\mathrm{HF}}=0.0$ becoming predominantly (90\%) HS at $a_{\mathrm{HF}}=0.3$ or higher (ESI, $\dagger$ Table S18). The $4 \mathrm{~d}$ TMCs almost exclusively favor LS states at $a_{\mathrm{HF}}=0.0$, and a much smaller number (i.e., 28) of TMCs, typically with Tc(III) and to a lesser extent Tc(II) or Mo(II), becoming HS-favored at $a_{\mathrm{HF}}=0.3$ (ESI, $\uparrow$ Table S18). Thus, based on this analysis, the $4 \mathrm{~d}$ TMC LS-bias with respect to $3 \mathrm{~d}$ TMCs combined with reduced exchange sensitivity also makes the 4d TMC HS/LS preferences significantly less sensitive to $a_{\mathrm{HF}}$ values.

Ultimately, to quantify the effect of HF exchange on $3 \mathrm{~d} / 4 \mathrm{~d}$ TMC ground state (GS) assignment, we extended the comparison of spin-state energetics to include IS states. There are 155 $\mathrm{d}^{4}-\mathrm{d}^{6} 3 \mathrm{~d} / 4 \mathrm{~d}$ TMC pairs for which all three (i.e., HS, IS, and LS) spin states and the spin-splitting energy sensitivities are computed. We combine these pairs with the $92 \mathrm{~d}^{3}$ or $\mathrm{d}^{7} 3 \mathrm{~d} / 4 \mathrm{~d}$ TMC pairs for which only two states were accessible (i.e., IS and LS), and their energies are computed. Over this 247-complex set, significant differences in the sensitivity of GS assignment to $a_{\mathrm{HF}}$ are apparent between $3 \mathrm{~d}$ and $4 \mathrm{~d}$ TMCs (Fig. 8). Namely, the number of $\mathrm{HS}$ ground states rises from around one in five at $a_{\mathrm{HF}}=0.0$ to over half at $a_{\mathrm{HF}}=0.3$ for $3 \mathrm{~d}$ TMCs, whereas none of the $4 \mathrm{~d}$ TMCs have a HS GS at any $a_{\mathrm{HF}}$ value (Fig. 8 and ESI, $\dagger$ Tables S19, S20). The proportion of IS states remains roughly constant for $3 \mathrm{~d}$ TMCs over this range, although their identities shift with added exchange to predominantly $\mathrm{d}^{3} / \mathrm{d}^{7}$ TMCs (i.e., excluding only two Mn(III) and one Cr(II) complex, ESI, $\dagger$ Table S19). The 4d TMCs differ from 3d TMCs because most have either an IS (ca. 35\%) or LS (ca. 65\%) GS, with almost no change in this distribution with $a_{\mathrm{HF}}$ value (Fig. 8 and ESI, $\dagger$ Table S19). While all 3d metal/oxidation states have at least one GS change from $a_{\mathrm{HF}}=0.0$ to 0.3 , only a small number (i.e., 5 of 45 ) of $\mathrm{d}^{3} \mathrm{Mo}$ (III) $4 \mathrm{~d}$ TMCs change from LS to IS over this range (Fig. 8 and ESI, $\dagger$ Table S19). This change in GS is somewhat larger than 


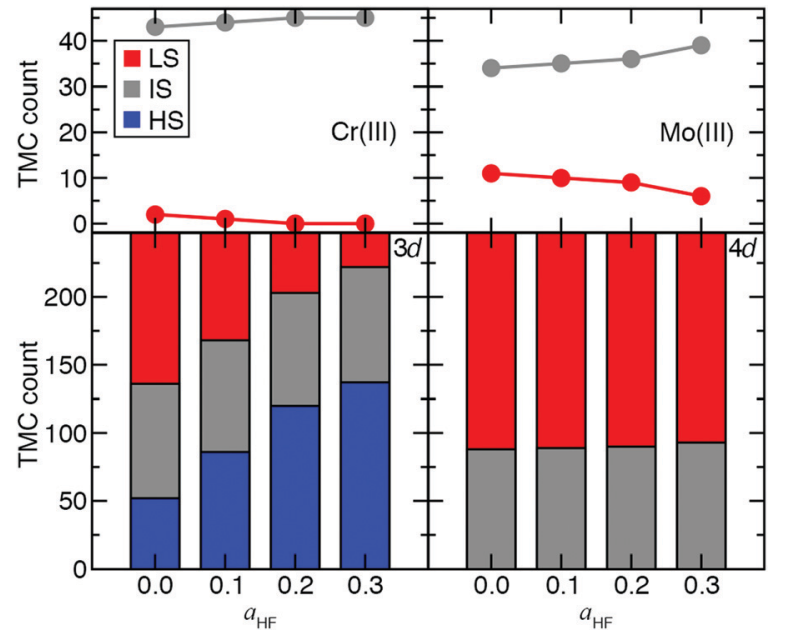

Fig. 8 Ground state assignment for the 247 for the 247 -complex set of $3 d$ and 4d TMC pairs: LS (red bars and circles), IS (gray bars and circles), and HS (blue bars). (top) Number of 47 pairs that are LS or IS for $\mathrm{d}^{3} \mathrm{Cr}$ (III) (left) or Mo(III) (right) with $a_{\mathrm{HF}}$ fraction. (bottom) Stacked bar plot of HS, IS, and LS ground states for all $3 d$ (left) and $4 d$ (right) TMCs with $a_{H F}$ fraction.

for the Cr(III) TMCs, which are all IS for $a_{\mathrm{HF}}=0.2$ or above (Fig. 8 and ESI, $\dagger$ Table S19). The $\mathrm{d}^{4} \mathrm{Mo}$ (II) and Tc(III) TMCs favor IS ground states exclusively, whereas most of the $3 \mathrm{~d}$ isovalent $\mathrm{Cr}$ (II) or Mn(III) TMCs are HS-favoring especially with increasing $a_{\mathrm{HF}}$ values (ESI, $\dagger$ Table S19). Thus, overall 4d TMC GS assignment is significantly less likely to be affected by a change in functional than an equivalent $3 \mathrm{~d}$ TMC although the sensitivity of predicted energies to exchange fraction is only on average reduced by around one third from the first- to second-row TMCs.

\section{e. Relationships between energetic sensitivity and structure}

In 3d TMCs, increasing spin multiplicity typically leads to longer metal-ligand bond lengths as antibonding states become preferentially occupied over states with bonding character, and this effect is more significant with increasing ligand field. Bond lengths do not change significantly with $a_{\mathrm{HF}}$ value, ${ }^{138}$ and thus structural differences between spin states are also invariant. To determine if structural differences between $3 \mathrm{~d}$ and $4 \mathrm{~d}$ TMC pairs could explain distinct exchange sensitivities due to increased diffuseness of the $4 \mathrm{~d}$ orbitals, we compared the B3LYP structures (i.e., metal-ligand bond lengths) of isovalent complexes. In both $3 \mathrm{~d}$ and $4 \mathrm{~d}$ TMCs, increasing spin multiplicity leads to longer metal-ligand bond lengths, consistent with our expectations, but bond lengths differ primarily due to the different sizes of $3 \mathrm{~d}$ and $4 \mathrm{~d}$ metals (ESI, $\dagger$ Fig. S3 and Table S21).

As in previous work, ${ }^{138}$ we facilitate comparison by focusing on relative metal-ligand bond lengths, $d_{\mathrm{rel}}$ :

$$
d_{\mathrm{rel}}(\mathrm{M}-\mathrm{L})=\frac{d(\mathrm{M}-\mathrm{L})}{r_{\mathrm{M}}+r_{\mathrm{L}}}
$$

obtained by computing the ratio of the bond length, $d$, obtained from B3LYP with respect to the substituent metal (M) or ligand (L) atoms' covalent radii, $r$ (ESI, $\dagger$ Table S21). The $d_{\text {rel }}$ values averaged over all six metal-ligand bonds have a similar range of values for both $3 \mathrm{~d}$ and $4 \mathrm{~d}$ TMCs; this averaging works better for the more symmetric LS states than HS or IS states (ESI, $\dagger$ Fig. S4-S6 and Tables S22, S23). For all TMCs, the $d_{\text {rel }}$ values increase on average by 0.1 from LS to HS states and increase by about half ( $\mathrm{ca}$. 0.05) that amount from LS to IS states (ESI, $\dagger$ Fig. S4 and Tables S22, S23).

For 3d TMCs, the $d_{\text {rel }}$ difference, $\Delta d_{\text {rel }}$, between HS and LS states is well correlated $\left(R^{2}=0.86\right)$ with $S\left(\Delta E_{\mathrm{H}-\mathrm{L}}\right)$ values (Fig. 9 and ESI, $\dagger$ Table S24). The Fe(II)(CO) ${ }_{6} \Delta d_{\text {rel }}$ is among the largest, consistent with the large magnitude (ca. $-175 \mathrm{kcal} \mathrm{mol}^{-1}$ $\left.\mathrm{HFX}^{-1}\right)$ of its $S\left(\Delta E_{\mathrm{H}-\mathrm{L}}\right)$, while $\mathrm{Mn}(\mathrm{III})\left(\mathrm{H}_{2} \mathrm{O}\right)_{6}$ has both a much lower $S\left(\Delta E_{\mathrm{H}-\mathrm{L}}\right)\left(c a . \quad-50 \mathrm{kcal} \mathrm{mol}^{-1} \mathrm{HFX}^{-1}\right)$ and $\Delta d_{\mathrm{rel}}$ of 0.04 (Fig. 9). In line with these observations, the overall largest HS-LS $\Delta d_{\text {rel }}$ values are observed for the cases with the most positive $\Delta E_{\mathrm{H}-\mathrm{L}}$ values (ESI, $\dagger$ Fig. S7). As with HS-LS, a similar relationship can be observed for $S(\Delta E)$ and $\Delta d_{\text {rel }}$ for the $3 \mathrm{~d}$ TMC HS-IS or IS-LS splittings (ESI, $\uparrow$ Fig. S8 and Table S24). In fact a single good correlation $\left(R^{2}=0.81\right)$ can be fit through all three sets of $S(\Delta E)$ and $\Delta d_{\text {rel }}$ values for 3d TMCs (Fig. 9 and ESI, $\dagger$ Fig. S8 and Table S24). Taken together with our prior findings, ${ }^{29}$ these observations suggest that increasing $a_{\mathrm{HF}}$ penalizes the delocalized, highly bonded lower-spin states more strongly than higher-spin states. When this bonding difference is larger, the sensitivity to $a_{\mathrm{HF}}$ is also higher.

For the second-row transition metals, there is also a good correlation $\left(R^{2}=0.71\right)$ between $S(\Delta E)$ and $\Delta d_{\text {rel }}$ for the HS-LS states of the $4 \mathrm{~d}$ TMCs (Fig. 9 and ESI, $\dagger$ Fig. S9, Table S24).

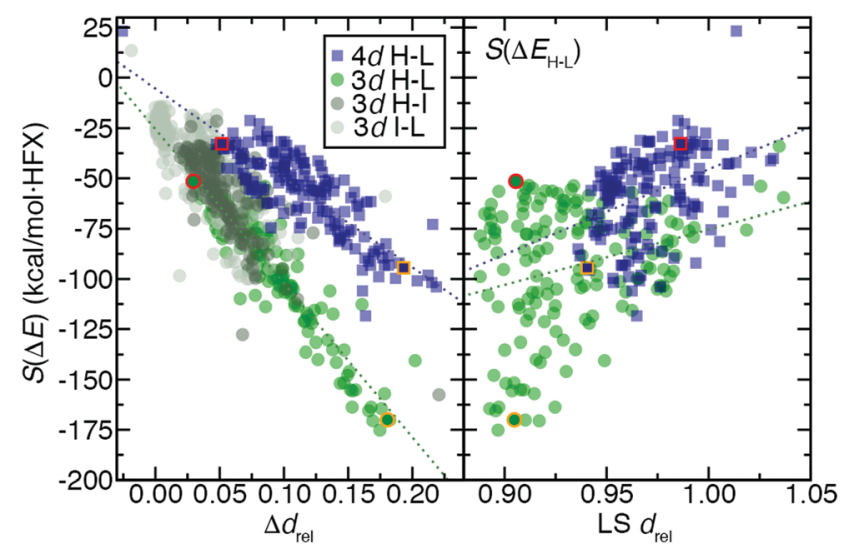

Fig. 9 Trends of exchange sensitivity of spin-splitting energies, $S(\Delta E)$ (in $\mathrm{kcal} \mathrm{mol}^{-1} \mathrm{HFX}^{-1}$ ), with averaged relative distance, $d_{\text {rel, }}$ quantities: (left) difference in $d_{\text {rel }}$ between spin states, $\Delta d_{\text {rel }}$, and (right) LS $d_{\text {rel. }}$. The $\Delta d_{\text {rel }} v s$. $S(\Delta E)$ trends (left) are shown for 155 pairs of $3 d$ TMCs in the case of 4-electron $\Delta E_{\mathrm{H}-\mathrm{L}}$ (green translucent circles), 2-electron $\Delta E_{\mathrm{H}-\mathrm{I}}$ (dark gray translucent circles), and 2-electron $\Delta E_{1-L}$ (light gray translucent circles, with an additional $92 \mathrm{I}-\mathrm{L}$-only pairs). The results for $4 \mathrm{~d}$ TMCs for the 4-electron $\Delta E_{\mathrm{H}-\mathrm{L}}$ case only are also shown (blue translucent squares). Best-fit lines are shown for all $3 d$ (green dotted line) or $4 d$ data (blue dotted line). The LS $d_{\text {rel }}$ trends $v s$. $S\left(\Delta E_{\mathrm{H}-\mathrm{L}}\right)$ only are shown at right and follow the same coloring scheme for both symbols and best-fit lines as indicated in left inset legend. For both plots, representative hexa-aqua $\mathrm{Mn}(\mathrm{III}) / \mathrm{TC}$ (III) HS-LS complex pairs are shown as solid symbols with red outline, and representative hexa-carbonyl Fe(II)/Ru(॥) HS-LS complex pairs are shown as solid symbols with orange outline. 
The slope of the relationship however is reduced with respect to the value for $3 \mathrm{~d}$ TMCs (Fig. 9 and ESI, $\dagger$ Table S24). Indeed, $\Delta d_{\text {rel }}$ values across all spin-state pairs in $4 \mathrm{~d}$ TMCs are as large as those for the $3 \mathrm{~d}$ TMCs. Thus, more diffuse $4 \mathrm{~d}$ orbitals do not change $\Delta d_{\text {rel }}$ value trends and cannot be used to explain the reduced exchange sensitivity of $4 \mathrm{~d}$ TMCs (ESI, $\dagger$ Fig. S4). A weaker, but somewhat unified, relationship can be observed between the LS state $d_{\text {rel }}$, which is generally longer in some but not all $4 \mathrm{~d}$ TMCs, and $S\left(\Delta E_{\mathrm{H}-\mathrm{L}}\right)$ across both $3 \mathrm{~d}$ and $4 \mathrm{~d}$ TMCs (Fig. 9 and ESI, $\dagger$ Table S24, Fig. S4).

To understand the origins of this relationship, we obtained potential energy curves (PECs) with varied metal-ligand bond length and varied $a_{\mathrm{HF}}$ values for $3 \mathrm{~d}$ Fe(II) and $4 \mathrm{~d} \mathrm{Ru}$ (II) TMCs in their quintet HS and singlet LS states. We contrasted homoleptic helium-atom $3 \mathrm{~d} / 4 \mathrm{~d}$ complexes as a simplified example of the weak-field limit with strong-field, hexa-carbonyl $3 \mathrm{~d} / 4 \mathrm{~d}$ TMCs, in which we rigidly displaced the CO ligands (see Section 2). The closed-shell He atoms act as very weak field ligands, with the $3 \mathrm{~d} / 4 \mathrm{~d}$ TMCs both strongly favoring the HS state over the LS state (B3LYP $\Delta E_{\mathrm{H}-\mathrm{L}}$ : Fe(II) ca. $-64 \mathrm{kcal} \mathrm{mol}^{-1}$ and $\mathrm{Ru}(\mathrm{II}) c a .-31 \mathrm{kcal} \mathrm{mol}^{-1}$, Fig. 10 and see ESI, $\dagger$ Table S25). The $S\left(\Delta E_{\mathrm{H}-\mathrm{L}}\right)$ values are both small and comparable (Fe(II): -47 vs. $\mathrm{Ru}(\mathrm{II}):-43 \mathrm{kcal} \mathrm{mol}^{-1} \mathrm{HFX}^{-1}$ ), consistent with small $S\left(\Delta E_{\mathrm{H}-\mathrm{L}}\right)$ values (hexa-aqua $\mathrm{Fe}(\mathrm{II}):-53$ vs. $\mathrm{Ru}(\mathrm{II}):-38 \mathrm{kcal} \mathrm{mol}^{-1}$ $\mathrm{HFX}^{-1}$ ) from other weak-field TMCs (ESI, $\dagger$ Tables S12 and S25). Despite these comparable exchange sensitivities, the dependence on $a_{\mathrm{HF}}$ of individual PECs of Ru(II) and Fe(II) TMCs is distinct (Fig. 10). Both HS and LS Ru(II)(He) ${ }_{6}$ PECs are stabilized with increasing $a_{\mathrm{HF}}$, but the HS relative energy is more sensitive

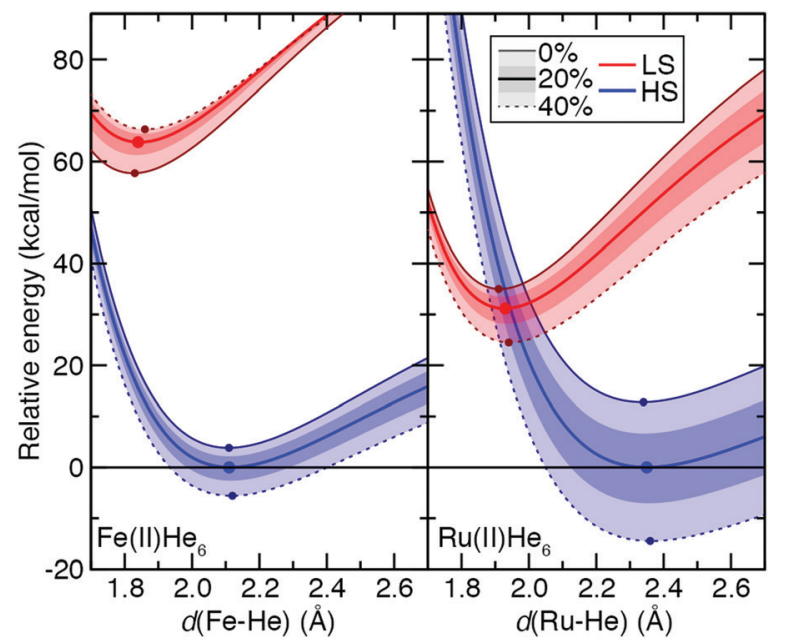

Fig. 10 Potential energy curves (PECs, in $\mathrm{kcal} \mathrm{mol}^{-1}$ ) with $\mathrm{M}$-He distance (in $\AA$ ) for $\mathrm{Fe}(॥)(\mathrm{He})_{6}$ (left) and $\mathrm{Ru}\left({ }^{\prime \prime}\right)(\mathrm{He})_{6}$ (right) in LS singlet (red) and HS quintet (blue) spin states. Solid center lines (red for LS and blue for LS, as indicated in inset legend) correspond to the B3LYP ( $\left.a_{\mathrm{HF}}=0.2\right)$ PEC, the outer solid line (maroon for LS and dark blue for $\mathrm{HS}$ ) corresponds to $a_{\mathrm{HF}}=$ 0.0 , and the outer dashed line corresponds to $a_{\mathrm{HF}}=0.4$ (as indicated also in inset legend). The inner shaded regions correspond to the $a_{\mathrm{HF}}=0.1-0.3$ range, and the outer shaded region to $a_{\mathrm{HF}}=0.0-0.4$. The relative energies have been aligned to set the minimum of the B3LYP PEC to zero, and a zero line is shown. A circle indicates the minimum of the PECs for $a_{\mathrm{HF}}=0.0,0.2$, and 0.4 . to exchange (Fig. 10). For $\mathrm{Fe}(\mathrm{II})(\mathrm{He})_{6}$, on the other hand, the HS PEC is stabilized with increasing $a_{\mathrm{HF}}$ while the LS is destabilized (Fig. 10). For individual LS or HS states, Ru(II) TMCs PECs have higher sensitivities than the Fe(II) counterparts (Fig. 10 and ESI, $\dagger$ Table S25). The negative $S\left(\Delta E_{\mathrm{H}-\mathrm{L}}\right)$ for $\mathrm{Fe}(\mathrm{II})(\mathrm{He})_{6}$ arises from additive sensitivities of the HS and LS states, while for $\mathrm{Ru}(\mathrm{II})(\mathrm{He})_{6}$ the simultaneous LS and HS stabilization leads to a comparable net $S\left(\Delta E_{\mathrm{H}-\mathrm{L}}\right)$ (Fig. 10 and ESI, $\dagger$ Table S25).

The He complexes are weakly bound, with the small covalent radius of the He atom leading to a very long estimated $d_{\text {rel }}$ values in LS states for both $3 \mathrm{~d}$ and $4 \mathrm{~d}$ TMCs (Fe(II): $d_{\text {rel }}=1.08 v s$. $\left.\mathrm{Ru}(\mathrm{II}): d_{\text {rel }}=1.11\right)$ despite moderate absolute bond lengths of 1.84 and $1.93 \AA$ A, respectively (Fig. 10 and ESI, $\dagger$ Tables S21, S25). The HS states are even more weakly bound, with large $\Delta d_{\text {rel }}$ values of 0.16 for $\mathrm{Fe}(\mathrm{II})$ and 0.24 for $\mathrm{Ru}(\mathrm{II})$, and these observations are insensitive to $a_{\mathrm{HF}}$ (Fig. 10 and ESI, $\dagger$ Table S25). Since we can obtain the exchange sensitivity over a wide range of M-He bond lengths in these TMCs, we also evaluated the extent to which $S$ values vary at points away from equilibrium (Fig. 10). The vertical HS-LS sensitivity evaluated at the LS geometry for $\mathrm{Ru}(\mathrm{II})$ or $\mathrm{Fe}(\mathrm{II})$ is comparable to that for the adiabatic case, despite the fact that the LS-HS ordering is inverted at the LS geometry for $\mathrm{Ru}$ (II) but unchanged for Fe(II) (Fig. 10 and ESI, $\dagger$ Table S25). When stretched to the HS geometry, the $S$ values decrease significantly for both Ru(II) and Fe(II) (Fig. 10 and ESI, $\dagger$ Table S25).

While the ground state preferences for model strong-field complexes of both $\mathrm{Fe}$ (II) and Ru(II) are uniformly LS (B3LYP $\Delta E_{\mathrm{H}-\mathrm{L}}: \mathrm{Fe}(\mathrm{II}) c a .30 \mathrm{kcal} \mathrm{mol}^{-1}$ and $\mathrm{Ru}(\mathrm{II}) c a .116 \mathrm{kcal} \mathrm{mol}^{-1}$ ), the exchange sensitivity trends are comparable to the weak-field $\mathrm{He}$ case (Fig. 11 and ESI, $\dagger$ Table S26). That is, larger total energy sensitivity in the $\mathrm{HS} \mathrm{Ru}(\mathrm{II})$ PEC still leads to a lower overall $S\left(\Delta E_{\mathrm{H}-\mathrm{L}}\right)$ magnitude compared to $\mathrm{Fe}(\mathrm{II})$ because exchange destabilizes the LS 3d TMC while weakly stabilizing the LS 4d TMC (Fig. 11 and ESI, $\dagger$ Table S26). The only significant distinction observed for the strong-field CO ligands is that $S$ for each PEC and the splitting is much more dependent on bond length, with the effect of significantly reducing $(>50 \%) S$ values for vertical spin-state energetics with respect to adiabatic $S\left(\Delta E_{\mathrm{H}-\mathrm{L}}\right)$ values (Fig. 11 and ESI, $\uparrow$ Table S26).

From the set of all 3d/4d TMC pairs, over 25 3d TMCs have positive sensitivities of the LS total energies whereas only one of the $4 \mathrm{~d}$ TMCs does (ESI, $\uparrow$ Table S27). While average sensitivities of the total energy with respect to $a_{\mathrm{HF}}$ are higher for both states in 4d TMCs, they are more likely to be similar in magnitude between LS and HS states. Thus, distinct geometric and electronic structure of the LS states of 3d TMCs likely contributes to their higher exchange sensitivity (ESI, $\uparrow$ Table S27).

\section{Conclusions}

We have carried out a comprehensive study of the extent to which established trends in 3d TMC exchange sensitivity and spin-state ordering have analogies in equivalent, isovalent $4 \mathrm{~d}$ TMCs. From ten ligands covering a wide range of ligand field 


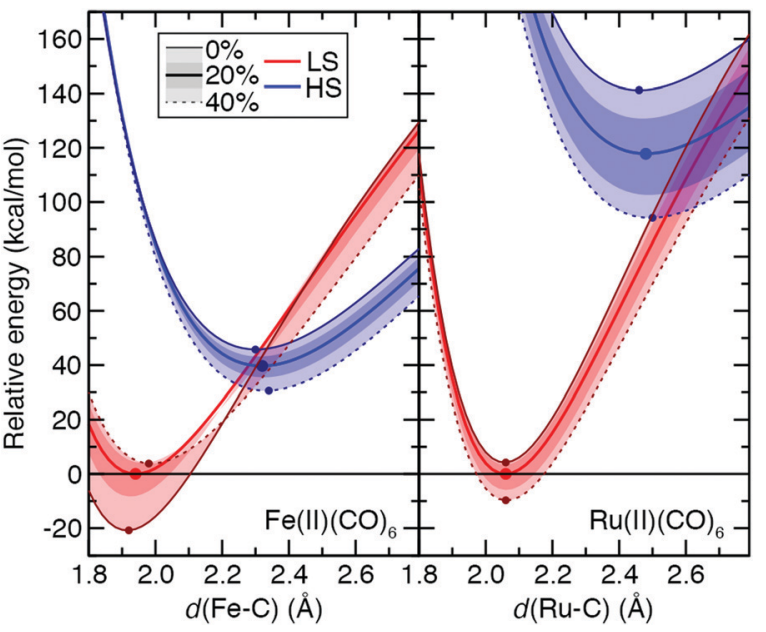

Fig. 11 Potential energy curves (PECs, in $\mathrm{kcal} \mathrm{mol}^{-1}$ ) with $\mathrm{M}-\mathrm{C}$ distance (in $\AA$ ) for $\mathrm{Fe}(॥)(\mathrm{CO})_{6}$ (left) and $\mathrm{Ru}(\|)(\mathrm{CO})_{6}$ (right) in LS singlet (red) and $\mathrm{HS}$ quintet (blue) spin states. Solid center lines (red for LS and blue for LS, as indicated in inset legend) correspond to the B3LYP $\left(a_{\mathrm{HF}}=0.2\right)$ PEC, the outer solid line (maroon for LS and dark blue for HS) corresponds to $a_{\mathrm{HF}}=$ 0.0 , and the outer dashed line corresponds to $a_{\mathrm{HF}}=0.4$ (as indicated also in inset legend). The inner shaded regions correspond to the $a_{\mathrm{HF}}=0.1-0.3$ range, and the outer shaded region to $a_{\mathrm{HF}}=0.0-0.4$. The relative energies have been aligned to set the minimum of the B3LYP PEC to zero, and a zero line is shown. A circle indicates the minimum of the PECs for $a_{\mathrm{HF}}=0.0,0.2$, and 0.4 .

strengths, we generated hundreds of homoleptic and heteroleptic TMCs with a range of mid-row $\mathrm{M}$ (II)/M(III) $3 \mathrm{~d}$ and $4 \mathrm{~d}$ metal centers to interpret both 4-electron (i.e., HS-LS) and 2-electron (i.e., HS-IS or IS-LS) spin-splitting energies and sensitivities. We observed consistently increasing exchange sensitivity of $\Delta E_{\mathrm{H}-\mathrm{L}}$ with increasing ligand field in both $3 \mathrm{~d}$ and $4 \mathrm{~d}$ homoleptic TMCs. Over the larger data set, we made a number of surprising observations:

(1) Strong-field ligand effects were found to be additive in heteroleptics for both $\Delta E_{\mathrm{H}-\mathrm{L}}$ and $S\left(\Delta E_{\mathrm{H}-\mathrm{L}}\right)$. Similar trends were observed for HS-IS and IS-LS spin-state energetics, albeit with all magnitudes and ligand field sensitivities reduced.

(2) The 4d TMC exchange sensitivities were consistently smaller in magnitude than the equivalent $3 \mathrm{~d}$ TMC sensitivities for all metals and oxidation states considered, and this deviation between $3 \mathrm{~d}$ and $4 \mathrm{~d}$ TMCs increased with increasing ligand field strength.

(3) Despite 4d TMC energetics being less sensitive than their 3d TMC counterparts, variations by as much as $10 \mathrm{kcal} \mathrm{mol}^{-1}$ per $10 \%$ change in $\mathrm{HF}$ exchange were still observed, which could have a significant effect on energetic predictions.

(4) Combined with the significant LS-shifting of 4d TMCs with respect to their equivalent $3 \mathrm{~d}$ TMCs, the reduced $4 \mathrm{~d}$ TMC exchange sensitivity led to a much lower likelihood of change in spin-state ordering than for their $3 \mathrm{~d}$ TMC counterparts. While over the range of $a_{\mathrm{HF}}=0.0$ to 0.3 many $3 \mathrm{~d}$ TMCs changed ground states from LS to IS or HS states, a very small number of 4d TMCs shifted from LS to IS and none were HS.

(5) Delocalization does not explain the reduced exchange sensitivity of $4 \mathrm{~d}$ TMCs. The $3 \mathrm{~d}$ and $4 \mathrm{~d}$ bond length differences between spin states were comparably large but could not explain the reduced sensitivity of $4 \mathrm{~d}$ TMCs.

(6) Analysis of PECs of representative complexes indicated the higher spin-splitting exchange sensitivities of $3 \mathrm{~d}$ TMCs is likely due to the opposing effects of exchange on the two spin states, despite higher exchange-sensitivity of the total energy in 4d TMCs.

Overall, we find that while spin-state energetics of $4 \mathrm{~d}$ TMCs are roughly two-thirds as sensitive as those of $3 \mathrm{~d}$ TMCs, this study suggests it is unlikely for HF exchange tuning to alter ground state predictions for $4 \mathrm{~d}$ TMCs. This does not guarantee that common DFT functionals are always capable of predicting the ground state spin but does suggest that conventional tuning approaches that work in $3 \mathrm{~d}$ TMCs to reproduce experimental spin state ordering will not be applicable in $4 \mathrm{~d}$ TMCs.

\section{Conflicts of interest}

The authors declare no competing financial interest.

\section{Acknowledgements}

The authors acknowledge primary support by the Office of Naval Research under grant numbers N00014-17-1-2956 and N00014-18-1-2434 (for D. H., N. A., and C. D.) and the National Science Foundation under grant number CBET-1704266 (for A. N.). This work was also supported by the Department of Energy under grant number DE-SC0018096 (for Y. C. and D. B. K. C.). A. N. was partially supported by a National Science Foundation Graduate Research Fellowship under Grant \#1122374. This work was carried out in part using computational resources from the Extreme Science and Engineering Discovery Environment (XSEDE), which is supported by National Science Foundation grant number ACI-1548562. H. J. K. holds a Career Award at the Scientific Interface from the Burroughs Wellcome Fund and an AAAS Marion Milligan Mason Award, which supported this work. The authors thank Adam H. Steeves for providing a critical reading of the manuscript.

\section{References}

1 H. Schwarz, Ménage-À-Trois: Single-Atom Catalysis, Mass Spectrometry, and Computational Chemistry, Catal. Sci. Technol., 2017, 7, 4302-4314.

2 D. Schröder, S. Shaik and H. Schwarz, Two-State Reactivity as a New Concept in Organometallic Chemistry, Acc. Chem. Res., 2000, 33, 139-145.

3 S. Shaik, D. Danovich, A. Fiedler, D. Schröder and H. Schwarz, Two-State Reactivity in Organometallic GasPhase Ion Chemistry, Helv. Chim. Acta, 1995, 78, 1393-1407.

4 T. Chantarojsiri, J. W. Ziller and J. Y. Yang, Incorporation of Redox-Inactive Cations Promotes Iron Catalyzed Aerobic C-H Oxidation at Mild Potentials, Chem. Sci., 2018, 9, 2567-2574. 
5 W. A. Hoffert, M. T. Mock, A. M. Appel and J. Y. Yang, Incorporation of Hydrogen-Bonding Functionalities into the Second Coordination Sphere of Iron-Based WaterOxidation Catalysts, Eur. J. Inorg. Chem., 2013, 3846-3857.

6 M. Foscato and V. R. Jensen, Automated in Silico Design of Homogeneous Catalysts, ACS Catal., 2020, 10, 2354-2377.

7 A. Bousseksou, G. Molnár and G. Matouzenko, Switching of Molecular Spin States in Inorganic Complexes by Temperature, Pressure, Magnetic Field and Light: Towards Molecular Devices, Eur. J. Inorg. Chem., 2004, 4353-4369.

8 S. Decurtins, P. Gütlich, C. Köhler, H. Spiering and A. Hauser, Light-Induced Excited Spin State Trapping in a Transition-Metal Complex: The Hexa-1-PropyltetrazoleIron (II) Tetrafluoroborate Spin-Crossover System, Chem. Phys. Lett., 1984, 105, 1-4.

9 A. Hauser, Light-Induced Spin Crossover and the HighSpin $\rightarrow$ Low-Spin Relaxation, Spin Crossover in Transition Metal Compounds II, Springer, 2004, pp. 155-198.

10 D. A. Reed, D. J. Xiao, M. I. Gonzalez, L. E. Darago, Z. R. Herm, F. Grandjean and J. R. Long, Reversible CO Scavenging via Adsorbate-Dependent Spin State Transitions in an Iron (II)-Triazolate Metal-Organic Framework, J. Am. Chem. Soc., 2016, 138, 5594-5602.

11 T. Groizard, N. Papior, B. Le Guennic, V. Robert and M. Kepenekian, Enhanced Cooperativity in Supported Spin-Crossover Metal-Organic Frameworks, J. Phys. Chem. Lett., 2017, 8, 3415-3420.

12 S. M. Neville, G. J. Halder, K. W. Chapman, M. B. Duriska, B. Moubaraki, K. S. Murray and C. J. Kepert, Guest Tunable Structure and Spin Crossover Properties in a Nanoporous Coordination Framework Material, J. Am. Chem. Soc., 2009, 131, 12106-12108.

13 S. Hedström, S. Chaudhuri, N. T. La Porte, B. Rudshteyn, J. F. Martinez, M. R. Wasielewski and V. S. Batista, Thousandfold Enhancement of Photoreduction Lifetime in Re (Bpy)(CO) 3 via Spin-Dependent Electron Transfer from a Perylenediimide Radical Anion Donor, J. Am. Chem. Soc., 2017, 139, 16466-16469.

14 C. J. Cramer and D. G. Truhlar, Density Functional Theory for Transition Metals and Transition Metal Chemistry, Phys. Chem. Chem. Phys., 2009, 11, 10757-10816.

15 P. Mori-Sánchez, A. J. Cohen and W. Yang, Many-Electron Self-Interaction Error in Approximate Density Functionals, J. Chem. Phys., 2006, 125, 201102.

16 A. Ruzsinszky, J. P. Perdew, G. I. Csonka, O. A. Vydrov and G. E. Scuseria, Density Functionals That Are One- and TwoAre Not Always Many-Electron Self-Interaction-Free, as Shown for $\mathrm{H}^{2+}, \mathrm{He}^{2+}, \mathrm{LiH}^{+}$, and $\mathrm{Ne}^{2+}$, J. Chem. Phys., 2007, 126, 104102.

17 R. Haunschild, T. M. Henderson, C. A. Jiménez-Hoyos and G. E. Scuseria, Many-Electron Self-Interaction and Spin Polarization Errors in Local Hybrid Density Functionals, J. Chem. Phys., 2010, 133, 134116.

18 A. J. Cohen, P. Mori-Sánchez and W. Yang, Insights into Current Limitations of Density Functional Theory, Science, 2008, 321, 792-794.
19 T. Schmidt and S. Kümmel, One- and Many-Electron SelfInteraction Error in Local and Global Hybrid Functionals, Phys. Rev. B, 2016, 93, 165120.

20 M.-C. Kim, E. Sim and K. Burke, Understanding and Reducing Errors in Density Functional Calculations, Phys. Rev. Lett., 2013, 111, 073003.

21 X. Zheng, M. Liu, E. R. Johnson, J. Contreras-García and W. Yang, Delocalization Error of Density-Functional Approximations: A Distinct Manifestation in Hydrogen Molecular Chains, J. Chem. Phys., 2012, 137, 214106.

22 E. R. Johnson, A. Otero-de-la-Roza and S. G. Dale, Extreme Density-Driven Delocalization Error for a Model SolvatedElectron System, J. Chem. Phys., 2013, 139, 184116.

23 A. Ruzsinszky, J. P. Perdew, G. I. Csonka, O. A. Vydrov and G. E. Scuseria, Spurious Fractional Charge on Dissociated Atoms: Pervasive and Resilient Self-Interaction Error of Common Density Functionals, J. Chem. Phys., 2006, 125, 194112.

24 A. D. Dutoi and M. Head-Gordon, Self-Interaction Error of Local Density Functionals for Alkali-Halide Dissociation, Chem. Phys. Lett., 2006, 422, 230-233.

25 T. Bally and G. N. Sastry, Incorrect Dissociation Behavior of Radical Ions in Density Functional Calculations, J. Phys. Chem. A, 1997, 101, 7923-7925.

26 Y. Zhang and W. Yang, A Challenge for Density Functionals: Self-Interaction Error Increases for Systems with a Noninteger Number of Electrons, J. Chem. Phys., 1998, 109, 2604-2608.

27 J. J. Determan, K. Poole, G. Scalmani, M. J. Frisch, B. G. Janesko and A. K. Wilson, Comparative Study of Nonhybrid Density Functional Approximations for the Prediction of 3d Transition Metal Thermochemistry, J. Chem. Theory Comput., 2017, 13, 4907-4913.

28 B. G. Johnson, C. A. Gonzales, P. M. W. Gill and J. A. Pople, A Density Functional Study of the Simplest Hydrogen Abstraction Reaction. Effect of Self-Interaction Correction, Chem. Phys. Lett., 1994, 221, 100-108.

29 T. Z. H. Gani and H. J. Kulik, Unifying Exchange Sensitivity in Transition Metal Spin-State Ordering and Catalysis through Bond Valence Metrics, J. Chem. Theory Comput., 2017, 13, 5443-5457.

30 T. Z. H. Gani and H. J. Kulik, Where Does the Density Localize? Convergent Behavior for Global Hybrids, Range Separation, and DFT+U, J. Chem. Theory Comput., 2016, 12, 5931-5945.

31 F. Liu and H. J. Kulik, Impact of Approximate DFT Density Delocalization Error on Potential Energy Surfaces in Transition Metal Chemistry, J. Chem. Theory Comput., 2020, 16, 264-277.

32 M. Srebro and J. Autschbach, Does a Molecule-Specific Density Functional Give an Accurate Electron Density? The Challenging Case of the Cucl Electric Field Gradient, J. Phys. Chem. Lett., 2012, 3, 576-581.

$33 \mathrm{~J}$. Autschbach and M. Srebro, Delocalization Error and "Functional Tuning" in Kohn-Sham Calculations of Molecular Properties, Acc. Chem. Res., 2014, 47, 2592-2602. 
34 H. J. Kulik, M. Cococcioni, D. A. Scherlis and N. Marzari, Density Functional Theory in Transition-Metal Chemistry: A Self-Consistent Hubbard U Approach, Phys. Rev. Lett., 2006, 97, 103001.

35 G. Ganzenmüller, N. Berkaïne, A. Fouqueau, M. E. Casida and M. Reiher, Comparison of Density Functionals for Differences between the High- (T2g5) and Low- (A1g1) Spin States of Iron(II) Compounds. IV. Results for the Ferrous Complexes [Fe(L)('NHS4')], J. Chem. Phys., 2005, 122, 234321.

36 A. Droghetti, D. Alfè and S. Sanvito, Assessment of Density Functional Theory for Iron (II) Molecules across the SpinCrossover Transition, J. Chem. Phys., 2012, 137, 124303.

37 E. I. Ioannidis and H. J. Kulik, Towards Quantifying the Role of Exact Exchange in Predictions of Transition Metal Complex Properties, J. Chem. Phys., 2015, 143, 034104.

38 S. R. Mortensen and K. P. Kepp, Spin Propensities of Octahedral Complexes from Density Functional Theory, J. Phys. Chem. A, 2015, 119, 4041-4050.

39 E. I. Ioannidis and H. J. Kulik, Ligand-Field-Dependent Behavior of Meta-GGA Exchange in Transition-Metal Complex Spin-State Ordering, J. Phys. Chem. A, 2017, 121, 874-884.

40 F. Liu, T. Yang, J. Yang, E. Xu, A. Bajaj and H. J. Kulik, Bridging the Homogeneous-Heterogeneous Divide: Modeling Spin and Reactivity in Single Atom Catalysis, Front. Chem., 2019, 7, 219.

41 O. S. Siig and K. P. Kepp, Iron(II) and Iron(III) Spin Crossover: Toward an Optimal Density Functional, J. Phys. Chem. A, 2018, 122, 4208-4217.

42 Q. M. Phung, C. Martín-Fernández, J. N. Harvey and M. Feldt, Ab Initio Calculations for Spin-Gaps of NonHeme Iron Complexes, J. Chem. Theory Comput., 2019, 15, 4297-4304.

43 M. Feldt, Q. M. Phung, K. Pierloot, R. A. Mata and J. N. Harvey, Limits of Coupled-Cluster Calculations for NonHeme Iron Complexes, J. Chem. Theory Comput., 2019, 15, 922-937.

44 Q. M. Phung, M. Feldt, J. N. Harvey and K. Pierloot, Toward Highly Accurate Spin State Energetics in First-Row Transition Metal Complexes: A Combined CASPT2/Cc Approach, J. Chem. Theory Comput., 2018, 14, 2446-2455.

45 S. Vancoillie, H. Zhao, M. Radon and K. Pierloot, Performance of CASPT2 and DFT for Relative Spin-State Energetics of Heme Models, J. Chem. Theory Comput., 2010, 6, 576-582.

46 J. K. Nørskov and T. Bligaard, The Catalyst Genome, Angew. Chem., Int. Ed., 2013, 52, 776-777.

47 A. Jain, S. P. Ong, G. Hautier, W. Chen, W. D. Richards, S. Dacek, S. Cholia, D. Gunter, D. Skinner, G. Ceder and K. A. Persson, Commentary: The Materials Project: A Materials Genome Approach to Accelerating Materials Innovation, APL Mater., 2013, 1, 011002.

48 KulikGroup molSimplify \& molSimplify Automatic Design. https://github.com/hjkgrp/molsimplify, accessed June 1, 2020.
49 D. P. Tabor, L. M. Roch, S. K. Saikin, C. Kreisbeck, D. Sheberla, J. H. Montoya, S. Dwaraknath, M. Aykol, C. Ortiz, H. Tribukait, C. Amador-Bedolla, C. J. Brabec, B. Maruyama, K. A. Persson and A. Aspuru-Guzik, Accelerating the Discovery of Materials for Clean Energy in the Era of Smart Automation, Nat. Rev. Mater., 2018, 3, 5-20.

50 S. Curtarolo, G. L. Hart, M. B. Nardelli, N. Mingo, S. Sanvito and O. Levy, The High-Throughput Highway to Computational Materials Design, Nat. Mater., 2013, 12, 191-201.

51 D. J. Durand and N. Fey, Computational Ligand Descriptors for Catalyst Design, Chem. Rev., 2019, 119, 6561-6594.

52 S. W. Gersten, G. J. Samuels and T. J. Meyer, Catalytic Oxidation of Water by an Oxo-Bridged Ruthenium Dimer, J. Am. Chem. Soc., 1982, 104, 4029-4030.

53 H.-W. Tseng, R. Zong, J. T. Muckerman and R. Thummel, Mononuclear Ruthenium (II) Complexes That Catalyze Water Oxidation, Inorg. Chem., 2008, 47, 11763-11773.

54 R. Zong and R. P. Thummel, A New Family of Ru Complexes for Water Oxidation, J. Am. Chem. Soc., 2005, 127, 12802-12803.

55 D. Merki and X. Hu, Recent Developments of Molybdenum and Tungsten Sulfides as Hydrogen Evolution Catalysts, Energy Environ. Sci., 2011, 4, 3878-3888.

56 S. Zakeeruddin, M. K. Nazeeruddin, P. Pechy, F. Rotzinger, R. Humphry-Baker, K. Kalyanasundaram, M. Grätzel, V. Shklover and T. Haibach, Molecular Engineering of Photosensitizers for Nanocrystalline Solar Cells: Synthesis and Characterization of Ru Dyes Based on Phosphonated Terpyridines, Inorg. Chem., 1997, 36, 5937-5946.

57 V. Jonas and W. Thiel, Theoretical Study of the Vibrational Spectra of the Transition Metal Carbonyls $\mathrm{M}(\mathrm{CO}) 6[\mathrm{M}=\mathrm{Cr}$, Mo, W], M (CO) 5 [M= Fe, Ru, Os], and M (CO) 4 [M= Ni, Pd, Pt], J. Chem. Phys., 1995, 102, 8474-8484.

58 M. P. Waller, H. Braun, N. Hojdis and M. Bühl, Geometries of Second-Row Transition-Metal Complexes from DensityFunctional Theory, J. Chem. Theory Comput., 2007, 3, 2234-2242.

59 M. L. Laury and A. K. Wilson, Performance of Density Functional Theory for Second Row (4 D) Transition Metal Thermochemistry, J. Chem. Theory Comput., 2013, 9, 3939-3946.

60 J. P. Perdew, R. G. Parr, M. Levy and J. L. Balduz, DensityFunctional Theory for Fractional Particle Number: Derivative Discontinuities of the Energy, Phys. Rev. Lett., 1982, 49, 1691-1694.

61 O. A. Vydrov, G. E. Scuseria and J. P. Perdew, Tests of Functionals for Systems with Fractional Electron Number, J. Chem. Phys., 2007, 126, 154109.

62 W. Yang, Y. Zhang and P. W. Ayers, Degenerate Ground States and a Fractional Number of Electrons in Density and Reduced Density Matrix Functional Theory, Phys. Rev. Lett., 2000, 84, 5172-5175.

63 J. P. Perdew and M. Levy, Physical Content of the Exact Kohn-Sham Orbital Energies: Band Gaps and Derivative Discontinuities, Phys. Rev. Lett., 1983, 51, 1884-1887.

64 L. J. Sham and M. Schlüter, Density-Functional Theory of the Energy Gap, Phys. Rev. Lett., 1983, 51, 1888-1891. 
65 E. Sagvolden and J. P. Perdew, Discontinuity of the Exchange-Correlation Potential: Support for Assumptions Used to Find It, Phys. Rev. A: At., Mol., Opt. Phys., 2008, 77, 012517.

66 P. Mori-Sanchez and A. J. Cohen, The Derivative Discontinuity of the Exchange-Correlation Functional, Phys. Chem. Chem. Phys., 2014, 16, 14378-14387.

67 A. Zunger and A. J. Freeman, Ground- and Excited-State Properties of LiF in the Local-Density Formalism, Phys. Rev. B: Solid State, 1977, 16, 2901-2926.

68 M. R. Pederson, R. A. Heaton and C. C. Lin, DensityFunctional Theory with Self-Interaction Correction: Application to the Lithium Molecule, J. Chem. Phys., 1985, 82, 2688-2699.

69 M. R. Pederson, A. Ruzsinszky and J. P. Perdew, Communication: Self-Interaction Correction with Unitary Invariance in Density Functional Theory, J. Chem. Phys., 2014, 140, 121103.

70 H. J. Kulik, Perspective: Treating Electron over-Delocalization with the DFT+U Method, J. Chem. Phys., 2015, 142, 240901.

71 V. I. Anisimov, J. Zaanen and O. K. Andersen, Band Theory and Mott Insulators - Hubbard-U Instead of Stoner-I, Phys. Rev. B: Condens. Matter Mater. Phys., 1991, 44, 943-954.

72 A. I. Liechtenstein, V. I. Anisimov and J. Zaanen, DensityFunctional Theory and Strong-Interactions - Orbital Ordering in Mott-Hubbard Insulators, Phys. Rev. B: Condens. Matter Mater. Phys., 1995, 52, R5467-R5470.

73 S. L. Dudarev, G. A. Botton, S. Y. Savrasov, C. J. Humphreys and A. P. Sutton, Electron-Energy-Loss Spectra and the Structural Stability of Nickel Oxide: An LSDA + U Study, Phys. Rev. B: Condens. Matter Mater. Phys., 1998, 57, 1505-1509.

74 L. Wilbraham, C. Adamo and I. Ciofini, Communication: Evaluating Non-Empirical Double Hybrid Functionals for Spin-State Energetics in Transition-Metal Complexes, J. Chem. Phys., 2018, 148, 041103.

75 J. L. Bao, L. Gagliardi and D. G. Truhlar, Self-Interaction Error in Density Functional Theory: An Appraisal, J. Phys. Chem. Lett., 2018, 9, 2353-2358.

76 B. G. Janesko, Reducing Density-Driven Error without Exact Exchange, Phys. Chem. Chem. Phys., 2017, 19, 4793-4801.

77 L. Wilbraham, P. Verma, D. G. Truhlar, L. Gagliardi and I. Ciofini, Multiconfiguration Pair-Density Functional Theory Predicts Spin-State Ordering in Iron Complexes with the Same Accuracy as Complete Active Space Second-Order Perturbation Theory at a Significantly Reduced Computational Cost, J. Phys. Chem. Lett., 2017, 8, 2026-2030.

78 C. Waitt, N. M. Ferrara and H. Eshuis, Thermochemistry and Geometries for Transition-Metal Chemistry from the Random Phase Approximation, J. Chem. Theory Comput., 2016, 12, 5350-5360.

79 F. Furche and J. P. Perdew, The Performance of Semilocal and Hybrid Density Functionals in 3d Transition-Metal Chemistry, J. Chem. Phys., 2006, 124, 044103.

80 Y. Zhao and D. G. Truhlar, The M06 Suite of Density Functionals for Main Group Thermochemistry, Thermochemical Kinetics, Noncovalent Interactions, Excited States, and Transition Elements: Two New Functionals and Systematic Testing of Four M06-Class Functionals and 12 Other Functionals, Theor. Chem. Acc., 2008, 120, 215-241.

81 M. Swart, A. R. Groenhof, A. W. Ehlers and K. Lammertsma, Validation of Exchange-Correlation Functionals for Spin States of Iron Complexes, J. Phys. Chem. A, 2004, 108, 5479-5483.

82 K. P. Jensen and J. Cirera, Accurate Computed Enthalpies of Spin Crossover in Iron and Cobalt Complexes, J. Phys. Chem. A, 2009, 113, 10033-10039.

83 S. Ye and F. Neese, Accurate Modeling of Spin-State Energetics in Spin-Crossover Systems with Modern Density Functional Theory, Inorg. Chem., 2010, 49, 772-774.

84 M. Swart, Accurate Spin-State Energies for Iron Complexes, J. Chem. Theory Comput., 2008, 4, 2057-2066.

85 B. G. Janesko, E. Proynov, J. Kong, G. Scalmani and M. J. Frisch, Practical Density Functionals Beyond the Overdelocalization-Underbinding Zero-Sum Game, J. Phys. Chem. Lett., 2017, 8, 4314-4318.

86 T. Stein, L. Kronik and R. Baer, Prediction of ChargeTransfer Excitations in Coumarin-Based Dyes Using a Range-Separated Functional Tuned from First Principles, J. Chem. Phys., 2009, 131, 244119.

87 S. Refaely-Abramson, R. Baer and L. Kronik, Fundamental and Excitation Gaps in Molecules of Relevance for Organic Photovoltaics from an Optimally Tuned Range-Separated Hybrid Functional, Phys. Rev. B: Condens. Matter Mater. Phys., 2011, 84, 075144.

88 L. Kronik, T. Stein, S. Refaely-Abramson and R. Baer, Excitation Gaps of Finite-Sized Systems from Optimally Tuned Range-Separated Hybrid Functionals, J. Chem. Theory Comput., 2012, 8, 1515-1531.

89 J. D. Gledhill, M. J. G. Peach and D. J. Tozer, Assessment of Tuning Methods for Enforcing Approximate Energy Linearity in Range-Separated Hybrid Functionals, J. Chem. Theory Comput., 2013, 9, 4414-4420.

90 A. Karolewski, L. Kronik and S. Kümmel, Using Optimally Tuned Range Separated Hybrid Functionals in GroundState Calculations: Consequences and Caveats, J. Chem. Phys., 2013, 138, 204115.

$91 \mathrm{H}$. Sun and J. Autschbach, Influence of the Delocalization Error and Applicability of Optimal Functional Tuning in Density Functional Calculations of Nonlinear Optical Properties of Organic Donor-Acceptor Chromophores, ChemPhysChem, 2013, 14, 2450-2461.

92 T. Körzdörfer and J.-L. Brédas, Organic Electronic Materials: Recent Advances in the DFT Description of the Ground and Excited States Using Tuned Range-Separated Hybrid Functionals, Acc. Chem. Res., 2014, 47, 3284-3291.

93 T. Leininger, H. Stoll, H.-J. Werner and A. Savin, Combining Long-Range Configuration Interaction with ShortRange Density Functionals, Chem. Phys. Lett., 1997, 275, 151-160.

94 H. Iikura, T. Tsuneda, T. Yanai and K. Hirao, A Long-Range Correction Scheme for Generalized-Gradient-Approximation Exchange Functionals, J. Chem. Phys., 2001, 115, 3540-3544. 
95 J. Toulouse, F. Colonna and A. Savin, Long-Range-ShortRange Separation of the Electron-Electron Interaction in Density-Functional Theory, Phys. Rev. A: At., Mol., Opt. Phys., 2004, 70, 062505.

96 R. Baer and D. Neuhauser, Density Functional Theory with Correct Long-Range Asymptotic Behavior, Phys. Rev. Lett., 2005, 94, 043002.

97 O. A. Vydrov and G. E. Scuseria, Assessment of a LongRange Corrected Hybrid Functional, J. Chem. Phys., 2006, 125, 234109.

98 E. Livshits and R. Baer, A Well-Tempered Density Functional Theory of Electrons in Molecules, Phys. Chem. Chem. Phys., 2007, 9, 2932-2941.

99 A. J. Cohen, P. Mori-Sánchez and W. Yang, Development of Exchange-Correlation Functionals with Minimal Many-Electron Self-Interaction Error, J. Chem. Phys., 2007, 126, 191109.

100 U. Salzner and R. Baer, Koopmans' Springs to Life, J. Chem. Phys., 2009, 131, 231101.

101 T. Tsuneda, J.-W. Song, S. Suzuki and K. Hirao, On Koopmans' Theorem in Density Functional Theory, J. Chem. Phys., 2010, 133, 174101.

102 A. Mahler, B. G. Janesko, S. Moncho and E. N. Brothers, When Hartree-Fock Exchange Admixture Lowers DFTPredicted Barrier Heights: Natural Bond Orbital Analyses and Implications for Catalysis, J. Chem. Phys., 2018, 148, 244106.

103 B. Pritchard and J. Autschbach, Theoretical Investigation of Paramagnetic NMR Shifts in Transition Metal Acetylacetonato Complexes: Analysis of Signs, Magnitudes, and the Role of the Covalency of Ligand-Metal Bonding, Inorg. Chem., 2012, 51, 8340-8351.

104 T. Duignan and J. Autschbach, Impact of the Kohn-Sham Delocalization Error on the $4 \mathrm{f}$ Shell Localization and Population in Lanthanide Complexes, J. Chem. Theory Comput., 2016, 12(7), 3109-3121.

105 T. Duignan, J. Autschbach, E. Batista and P. Yang, Assessment of Tuned Range Separated Exchange Functionals for Spectroscopies and Properties of Uranium Complexes, J. Chem. Theory Comput., 2017, 13(8), 3614-3625.

106 W. Jiang, N. J. DeYonker, J. J. Determan and A. K. Wilson, Toward Accurate Theoretical Thermochemistry of First Row Transition Metal Complexes, J. Phys. Chem. A, 2011, 116, 870-885.

107 K. A. Moltved and K. P. Kepp, The Metal Hydride Problem of Computational Chemistry: Origins and Consequences, J. Phys. Chem. A, 2019, 123, 2888-2900.

108 D. N. Bowman and E. Jakubikova, Low-Spin Versus HighSpin Ground State in Pseudo-Octahedral Iron Complexes, Inorg. Chem., 2012, 51, 6011-6019.

109 D. M. Smith, M. Dupuis and T. Straatsma, Multiplet Splittings and Other Properties from Density Functional Theory: An Assessment in Iron-Porphyrin Systems, Mol. Phys., 2005, 103, 273-278.

110 M. Bruschi, L. De Gioia, G. Zampella, M. Reiher, P. Fantucci and M. Stein, A Theoretical Study of Spin States in Ni-S4 Complexes and Models of the [NiFe] Hydrogenase Active Site, JBIC, J. Biol. Inorg. Chem., 2004, 9, 873-884.
111 P. Verma, Z. Varga, J. E. Klein, C. J. Cramer, L. Que and D. G. Truhlar, Assessment of Electronic Structure Methods for the Determination of the Ground Spin States of Fe (II), Fe (III) and Fe (IV) Complexes, Phys. Chem. Chem. Phys., 2017, 19, 13049-13069.

112 G. N. Simm and M. Reiher, Systematic Error Estimation for Chemical Reaction Energies, J. Chem. Theory Comput., 2016, 12, 2762-2773.

113 T. Stein, J. Autschbach, N. Govind, L. Kronik and R. Baer, Curvature and Frontier Orbital Energies in Density Functional Theory, J. Phys. Chem. Lett., 2012, 3, 3740-3744.

114 J. H. Skone, M. Govoni and G. Galli, Self-Consistent Hybrid Functional for Condensed Systems, Phys. Rev. B: Condens. Matter Mater. Phys., 2014, 89, 195112.

115 T. Shimazaki and Y. Asai, First Principles Band Structure Calculations Based on Self-Consistent Screened HartreeFock Exchange Potential, J. Chem. Phys., 2009, 130, 164702.

116 D. C. Ashley and E. Jakubikova, Ironing out the Photochemical and Spin-Crossover Behavior of Fe(II) Coordination Compounds with Computational Chemistry, Coord. Chem. Rev., 2017, 337, 97-111.

117 M. Reiher, Theoretical Study of the Fe (Phen) 2 (NCS) 2 Spin-Crossover Complex with Reparametrized Density Functionals, Inorg. Chem., 2002, 41, 6928-6935.

118 E. A. Bleda, C. Trindle and Z. Altun, Studies on Spin State Preferences in Fe(II) Complexes, Comput. Theor. Chem., 2015, 1073, 139-148.

119 J. P. Janet, L. Chan and H. J. Kulik, Accelerating Chemical Discovery with Machine Learning: Simulated Evolution of Spin Crossover Complexes with an Artificial Neural Network, J. Phys. Chem. Lett., 2018, 9, 1064-1071.

120 K. Burke, Perspective on Density Functional Theory, J. Chem. Phys., 2012, 136, 150901.

121 A. D. Becke, Perspective: Fifty Years of Density-Functional Theory in Chemical Physics, J. Chem. Phys., 2014, 140, 18 A301.

122 J. P. Janet, Q. Zhao, E. I. Ioannidis and H. J. Kulik, Density Functional Theory for Modelling Large Molecular Adsorbate-Surface Interactions: A Mini-Review and Worked Example, Mol. Simul., 2017, 43, 327-345.

123 R. J. Deeth and N. Fey, The Performance of Nonhybrid Density Functionals for Calculating the Structures and Spin States of Fe (II) and Fe (III) Complexes, J. Comput. Chem., 2004, 25, 1840-1848.

124 D. Coskun, S. V. Jerome and R. A. Friesner, Evaluation of the Performance of the B3LYP, PBE0, and M06 DFT Functionals, and DBLOC-Corrected Versions, in the Calculation of Redox Potentials and Spin Splittings for Transition Metal Containing Systems, J. Chem. Theory Comput., 2016, 12, 1121-1128.

125 T. F. Hughes and R. A. Friesner, Correcting Systematic Errors in DFT Spin-Splitting Energetics for Transition Metal Complexes, J. Chem. Theory Comput., 2011, 7, 19-32.

126 K. P. Kepp, Theoretical Study of Spin Crossover in 30 Iron Complexes, Inorg. Chem., 2016, 55, 2717-2727.

127 S. Zein, S. A. Borshch, P. Fleurat-Lessard, M. E. Casida and H. Chermette, Assessment of the Exchange-Correlation 
Functionals for the Physical Description of Spin Transition Phenomena by Density Functional Theory Methods: All the Same?, J. Chem. Phys., 2007, 126, 014105.

128 K. Boguslawski, C. R. Jacob and M. Reiher, Can DFT Accurately Predict Spin Densities? Analysis of Discrepancies in Iron Nitrosyl Complexes, J. Chem. Theory Comput., 2011, 7, 2740-2752.

129 P. Milko and M. A. Iron, On the Innocence of Bipyridine Ligands: How Well Do DFT Functionals Fare for These Challenging Spin Systems?, J. Chem. Theory Comput., 2014, 10, 220-235.

130 E. M. Sproviero, J. A. Gascon, J. P. McEvoy, G. W. Brudvig and V. S. Batista, Characterization of Synthetic Oxomanganese Complexes and the Inorganic Core of the O2-Evolving Complex in Photosystem II: Evaluation of the DFT/B3LYP Level of Theory, J. Inorg. Biochem., 2006, 100, 786-800.

131 M. Reiher, O. Salomon and B. A. Hess, Reparameterization of Hybrid Functionals Based on Energy Differences of States of Different Multiplicity, Theor. Chem. Acc., 2001, 107, 48-55.

132 O. Salomon, M. Reiher and B. A. Hess, Assertion and Validation of the Performance of the B3LYP* Functional for the First Transition Metal Row and the G2 Test Set, J. Chem. Phys., 2002, 117, 4729-4737.

133 A. Fouqueau, S. Mer, M. E. Casida, L. M. Lawson Daku, A. Hauser, T. Mineva and F. Neese, Comparison of Density Functionals for Energy and Structural Differences between the High- [5t2g: (T2g)4(Eg)2] and Low- [1a1g: (T2g)6(Eg)0] Spin States of the Hexaquoferrous Cation $[\mathrm{Fe}(\mathrm{H} 2 \mathrm{O}) 6]^{2+}$, J. Chem. Phys., 2004, 120, 9473-9486.

134 A. Fouqueau, M. E. Casida, L. M. Lawson Daku, A. Hauser and F. Neese, Comparison of Density Functionals for Energy and Structural Differences between the High[5t2g:(T2g) 4 (Eg) 2] and Low-[1a1g:(T2g) 6 (Eg) 0] Spin States of Iron (II) Coordination Compounds. II. More Functionals and the Hexaminoferrous Cation, $[\mathrm{Fe}$ (NH3) 6]2+, J. Chem. Phys., 2005, 122, 044110.

135 C. Adamo and V. Barone, Toward Reliable Density Functional Methods without Adjustable Parameters: The PBE0 Model, J. Chem. Phys., 1999, 110, 6158-6170.

136 J. P. Janet and H. J. Kulik, Predicting Electronic Structure Properties of Transition Metal Complexes with Neural Networks, Chem. Sci., 2017, 8, 5137-5152.

137 H. J. Kulik, Making Machine Learning a Useful Tool in the Accelerated Discovery of Transition Metal Complexes, Wiley Interdiscip. Rev.: Comput. Mol. Sci., 2020, 10, e1439.

138 M. G. Taylor, T. Yang, S. Lin, A. Nandy, J. P. Janet, C. Duan and H. J. Kulik, Seeing Is Believing: Experimental Spin States from Machine Learning Model Structure Predictions, J. Phys. Chem. A, 2020, 124, 3286-3299.

139 J. P. Janet, F. Liu, A. Nandy, C. Duan, T. Yang, S. Lin and H. J. Kulik, Designing in the Face of Uncertainty: Exploiting Electronic Structure and Machine Learning Models for Discovery in Inorganic Chemistry, Inorg. Chem., 2019, 58, 10592-10606.

140 R. Tsuchida, Absorption Spectra of Co-ordination Compounds. I, Bull. Chem. Soc. Jpn., 1938, 13, 388-400.

141 A. Nandy, C. Duan, J. P. Janet, S. Gugler and H. J. Kulik, Strategies and Software for Machine Learning Accelerated
Discovery in Transition Metal Chemistry, Ind. Eng. Chem. Res., 2018, 57, 13973-13986.

142 C. Duan, J. P. Janet, F. Liu, A. Nandy and H. J. Kulik, Learning from Failure: Predicting Electronic Structure Calculation Outcomes with Machine Learning Models, J. Chem. Theory Comput., 2019, 15, 2331-2345.

143 E. I. Ioannidis, T. Z. H. Gani and H. J. Kulik, molSimplify: A Toolkit for Automating Discovery in Inorganic Chemistry, J. Comput. Chem., 2016, 37, 2106-2117.

144 KulikGroup molSimplify Documentation, http://molsimplify. mit.edu, accessed June 1, 2020.

145 N. M. O’Boyle, M. Banck, C. A. James, C. Morley, T. Vandermeersch and G. R. Hutchison, Open Babel: An Open Chemical Toolbox, J. Cheminf., 2011, 3, 33.

146 N. M. O’Boyle, C. Morley and G. R. Hutchison, Pybel: A Python Wrapper for the Openbabel Cheminformatics Toolkit, Chem. Cent. J., 2008, 2, 5.

147 I. S. Ufimtsev and T. J. Martinez, Quantum Chemistry on Graphical Processing Units. 3. Analytical Energy Gradients, Geometry Optimization, and First Principles Molecular Dynamics, J. Chem. Theory Comput., 2009, 5, 2619-2628.

148 Petachem, http://www.petachem.com, accessed June 1, 2020.

149 A. D. Becke, Density-Functional Thermochemistry. III. The Role of Exact Exchange, J. Chem. Phys., 1993, 98, 5648-5652.

150 C. Lee, W. Yang and R. G. Parr, Development of the ColleSalvetti Correlation-Energy Formula into a Functional of the Electron Density, Phys. Rev. B: Condens. Matter Mater. Phys., 1988, 37, 785-789.

151 P. J. Stephens, F. J. Devlin, C. F. Chabalowski and M. J. Frisch, Ab Initio Calculation of Vibrational Absorption and Circular Dichroism Spectra Using Density Functional Force Fields, J. Phys. Chem., 1994, 98, 11623-11627.

152 P. J. Hay and W. R. Wadt, Ab Initio Effective Core Potentials for Molecular Calculations. Potentials for the Transition Metal Atoms Sc to $\mathrm{Hg}$, J. Chem. Phys., 1985, 82, 270-283.

153 V. R. H. Saunders and I. Hillier, A "Level-Shifting” Method for Converging Closed Shell Hartree-Fock Wave Functions, Int. J. Quantum Chem., 1973, 7, 699-705.

154 L.-P. Wang and C. Song, Geometry Optimization Made Simple with Translation and Rotation Coordinates, J. Chem. Phys., 2016, 144, 214108.

155 J. P. Janet, C. Duan, T. Yang, A. Nandy and H. J. Kulik, A Quantitative Uncertainty Metric Controls Error in Neural Network-Driven Chemical Discovery, Chem. Sci., 2019, 10, 7913-7922.

156 Q. Zhao and H. J. Kulik, Stable Surfaces That Bind Too Tightly: Can Range Separated Hybrids or DFT+U Improve Paradoxical Descriptions of Surface Chemistry?, J. Phys. Chem. Lett., 2019, 10, 5090-5098.

157 Q. Zhao and H. J. Kulik, Where Does the Density Localize in the Solid State? Divergent Behavior for Hybrids and DFT + U, J. Chem. Theory Comput., 2018, 14, 670-683.

158 P. Gütlich, Spin Crossover in Iron (II)-Complexes, Metal Complexes, Springer, 1981, pp. 83-195. 